\title{
Accessibility and Usability Of Health Information Tools As Predictors Of Clinical Decision Making Among Medical Doctors In Obafemi Awolowo University Teaching Hospital, Ile-Ife
}

\author{
Adegboye, Moyosore O \\ The author is a postgraduate student in Library and Information Studies at the Department of Communication \\ and General Studies in Federal University of Agriculture Abeokuta, Nigeria
}

adegboyemoyo@gmail.com

\begin{abstract}
The efficacy and indispensable role of information sources accessible and used by clinical specialists for clinical decision-making cannot be over emphasized. Thus, this investigation assessed the entrance and utilization of wellbeing data assets as indicators of clinical dynamic among clinical specialists in Obafemi Awolowo University Teaching Hospital Ile-Ife, Osun State. Arbitrary inspecting procedure was utilized to choose 265 clinical specialists from a populace of 822. Essential information were gotten on financial attributes of the respondents, level of availability, recurrence of utilization, different center aptitudes and difficulties obstructing the utilization of wellbeing data assets utilizing an organized survey and Focus bunch conversation (FGD). Information were dissected utilizing recurrence tallies, rates, mean, Pearson Product Moment Correlation (PPMC) and Multiple Regression. Results reveal that 59.8\% of the respondents were male while $51.1 \%$ were within the ages of 30-49 years. Many (54.8\%) of the respondents were married, while 41.7\% were registrars (junior and senior). Findings revealed that Computerized Tomography Scan $(\mathrm{CT} ; \bar{x}=3.49)$, electrocardiography machine (ECG; $\bar{x}=3.40)$, hatchery $(\bar{x}=3.15)$ and orthoscopic $(\bar{x}=$ $3.15)$ were the significant wellbeing data assets available for clinical dynamic among clinical specialists. Result additionally uncovered that ECG machine $(\bar{x}=3.84)$, VCD $(\bar{x}=3.82)$, web ( $\bar{x}=3.79)$, and remotely coordinating $(\bar{x}=3.78)$ were the every now and again got to wellbeing data assets. Much of the time used wellbeing data assets were; CT check $(\bar{x}=3.85)$, ECG machine $(\bar{x}=3.73)$ and web $(\bar{x}=3.62)$. Findings further revealed that pattern recognition from experience $(\bar{x}=3.32)$, critical thinking without emotion ( $\bar{x}=3.16)$, hypothesis updating $(\bar{x}=3.607)$ and perception based confidence $(\bar{x}=2.97)$ were the core skills used by clinical specialists in clinical decision making. The significant difficulties blocking the utilization of wellbeing data assets among clinical specialists for clinical dynamic were; ominous/conflicting government arrangements ( 3.15), financial status of clinical specialists ( $\bar{x}=3.14$ ), insufficient subsidizing $(\bar{x}=2.98)$ and
\end{abstract}


absence of prepared staff in wellbeing data administrations conveyance $(\bar{x}=2.95)$. The center gathering conversation accentuated that clinical specialists should possess critical thinking without emotions and good time pressure balance in order to make right clinical decisions. PPMC revealed significant relationships $(\mathrm{p}<$ $0.05)$ between access to health information tools $(\mathrm{r}=0.347)$, use of health information tools $(\mathrm{r}=0.352)$ and clinical decision making. Multiple regression reveal that access to health information tools $(\beta=6.203)$ and use of health information tools $(\beta=5.443)$ significantly $(p<0.05)$ decide clinical dynamic among clinical specialists. The investigation inferred that clinical specialists have great access and utilization of wellbeing data assets to settle on clinical choices in the examination region. The investigation consequently suggested regular trainings of medical personnel on health information tools to enhance accurate result and decision making by clinical specialists.

Published by IJRP.ORG. Selection and/or peer-review under responsibility of International Journal of Research Publications (IJRP.ORG)

Keywords: Clinical decision making; health information tools; Utilization; Clinical specialists.

\subsection{Introduction}

It is a common knowledge to all that clinical specialists' decisions have important implications on the outcome of health condition of patients. Clinical specialists are those individuals whose work include a scope of exercises identified with the consideration and treatment of a patient. Clinical specialists are generally involved in the activities that are geared towards the provision of health services including diagnosing, maintaining, or treating the patient's physical or mental condition, with the support of other of health workers. The activities that fall within health work in the context of this study include and not limited to administering a drug or other substance, chemotherapy; physical examination of a patient; dental or oral health examinations and treatment; psychological assessment; interventions such as blood and blood product transfusions; invasive procedures, surgical operations, oral health interventions; pathological and radiological investigations or procedures, for example, taking a blood sample or biopsy for analysis; manipulation or joint immobilization; screening undertaken for pathological conditions, for example, breast or bowel cancer; services provided by the allied health disciplines such as the application of splints or heat packs; the transfer of a patient to another facility; and clinical trials or medical research (Sketcher-Baker, 2017).

Clinical choice is a term regularly used to depict the basic job of the clinical specialists. It is, where information are accumulated, deciphered, and assessed to choose a proof based decision of activity. Dynamic can go from quick, instinctive, or heuristic choices through to very much contemplated, insightful, proof based choices that drive patient and customer care. Clinical specialists take part in a range of dynamic. Toward one side of the range, they utilize nature and experience to choose, where there is usually a high volume of clear decisions to be made. The commitments of clinical informatics to a clinical expert incorporate the advancement of information sharing, satisfactory wellbeing checking, insights gathering investigation, and the conveyance of powerful medical care administrations (Olatokun and Adeboyejo, 2009). 
(Daniel and Oyetunji, 2013) recognized different purposes in which clinical specialists use clinical informatics. Instances of such usage are the arrangement of sufficient admittance to proficient partners through moment transmission/receipt of mail message, electronic record framework, and force search utilities to find data put away in large number of PCs around the globe and compelling correspondence using web, and conclusion of patients. At the contrary completion of the variety, there may be marvelous decisions to be made, where the level of weakness is high and an intelligent and evidence based technique is required to help the standards based heuristics or experience we have gotten after some time in 'relative' conditions. A compelling expert is entrusted with settling on clinical choices with patients and customers commonly during their sheath and care venture. Clinical dynamic is an equilibrium of involvement, mindfulness, information and data gathering, utilizing suitable evaluation instruments, partners and proof based practice to control. Clinical specialists' dynamic is a massive assignment that frequently require chiefs to weigh genuine compromises, think about patients' qualities, and consolidate proof notwithstanding vulnerability. Clinical choices are settled on certainly by clinicians and other chiefs consistently. Choices dependent on close to home experience are dependent upon numerous predispositions. Choice investigation and cost-adequacy examination are methodical methodologies used to help dynamic under states of vulnerability that include significant compromises. These numerical devices can give patients, clinical specialists and strategy creators with a valuable way to deal with complex clinical dynamic. Many decisions that clinical specialists make in the course of their daily practice are part of routine medical care and involve little thought, uncertainty, or risk. However, decisions must also be made in diagnostic or treatment dilemmas for which there are no easy answers. Fusing proof, weighing troublesome compromises between possible advantages and hurts, and including patients' qualities for these results can be an extremely intricate test. Choice investigation and costadequacy examination are quantitative methods that give an efficient way to deal with coordinating proof inside the setting of a particular choice issue. Overall, boost the ideal result. Expected worth dynamic uses express qualities put on various results joined with the likelihood of those results as a manual for picking between alternatives. Expected worth is the thing that would happen by and large if the choice were consistently played out various occasions (Sox, Blatt, Higgins and Matron, 2007). It is basic information that during persistent conferences, essential consideration clinical specialists need understanding explicit data. Getting to data in an ideal way is fundamental for the clinical dynamic cycle. Data needs stay unanswered at the time the clinical specialists are settling on clinical choices, at that point postponed or ignorant choices may happen. Thusly, there might be clinical mistakes, for example, inaccurate analysis, blunder in regulating treatment or inability to give prophylactic treatment which impacts the quality and result of choices. Data needs of clinical specialists are characterized as articulations of missing data that is needed to achieve a particular undertaking, which for this situation is overseeing tolerant consideration (Van Osch, Wakker, Van nook Hout, and Stiggelbout, 2008). Data looking for conduct of the clinical specialists would then be able to be characterized as the manner in which clinical specialists look for and use data to fulfill their data need (Peul, Van den Hout, Brand, Thomeer and Koes, 2008). In addition, the recurrence of data needs that emerge during clinical discussions can go from one inquiry for each 10 patient experiences to four inquiries for every experience (Weinstein, Lurie \& Tosteson, 2006). The tools that the clinical specialists use are an important topic to investigate because the information use by the clinical specialists depends largely on the accessible information. Information tools are used by the clinical specialists to supplement their knowledge and clinical experience and to keep themselves up to date. Electronic clinical information tools continue to expand in accessibility and are an important reference for the clinical specialists. Further, designers of electronic data assets are incorporating these productive and powerful assets with clinical data frameworks (CISs) to help the data needs of the clinical specialists. Access to adequate medical information is imperative for successful healthcare delivery, particularly, for clinical specialists all over the world. (Moon, Hossain and Shin, 2012) admit that access to accurate medical information, in various health care facilities, is very necessary for 
clinical specialists to take effective medical decision. (Attama \& Ezema, 2005) argue that access and use of information are necessary for clinical specialists for problem solving and decision making.

However, clinical specialists' utilization of these assets is as yet affected by numerous constraints, for example, ease of use and significance to clinical errands. For instance, a data recovery framework's exhibition is reliant on the capacity of a client to change over their data need into a question that can be perceived by the recovery framework. Regular language inquiry frameworks are accessible, however the interpretation into an organized question is hard to achieve with exactness. Clinical specialists' information needs are oftentimes dismissed and there are various reasons shielding the clinical experts from tending to those necessities, for instance, nonappearance of time and capacities to complete look capably and absence of incorporation in the inquiry cycle into clinician work process. (Otero, Hersh, Luna, Gonzalez, 2002), observed that in primary care, the health workers only tried to find an answer to $23 \%$ of questions, and of those questions they did attempt to answer, they were successful in finding an answer $86 \%$ of the time. The low percentage for seeking answers to questions may be due to a time and workflow limitation during patient visits for these clinical specialists. In survey results by the Commonwealth fund, clinical specialists believed that spending more time with their patients is effective in improving patient care, and they were not satisfied with the limited time available for patient consultations. In a report by World Health Organisation's (WHO) 2006, World Health Report, 57 countries were faced with severe shortages in their healthcare workforce. Nuq (2012) demonstrated that there is a lack of 4.3 million specialists and other wellbeing laborers everywhere on the world, WHO estimates that there is a global shortage of approximately 4.3 million clinical specialists required for delivering essential healthcare services to populations in need. The role of health information technology in clinical practice is growing as well. More clinical specialists are using electronic health records (EHRs) which are 'patient records of health information created by encounters in any care delivery setting'. In some cases a doctor needs to audit the record of a patient's visit in an extremely definite manner, and different occasions, clinical specialists want a brisk depiction of what occurred. Absence of ease of use contemplations, for example, usability and value in the plan of EHR frameworks makes potential human-PC cooperation issues, including expanded work process unpredictability that may bring about loss of profitability and diminished nature of patient consideration (Weinstein, Siegel, Gold, Kamlet, Russell, Evans, Tavakoli and Crawford, 2004). While a number of studies have examined the information needs of clinical specialists, clinical specialists also have many responsibilities in the clinical setting, which include providing family planning and immunizations, and carrying out the treatment recommended by the health workers (Kassier \& Angela, 2005). Clinical specialists partner with other healthcare professionals to assess and treat the patient's problem, protect the patient by preventing infection and ensuring a safe and healthy environment, educate the patient and family about the proposed treatment plan given by the physician, and advocate for patients when necessary (Lawton \& Burns 2015). Wellbeing laborers should likewise have the option to work on as per flow rules and, subsequently, should be very much educated regarding research discoveries to keep educated about innovation, examination and patient consideration (Tosteson, Skinner, Lurie, Andersson and Berven, 2008). In an investigation by (Cogdill, 2006), clinical experts experienced data needs because of patient experiences and furthermore sought after responses for a bigger part of the clinical inquiries that emerge. There are numerous wellsprings of data accessible today for the clinical specialists to discover answers to their patient-related inquiries which may cause data over-burden. Bawden (2008) recommended that data over-burden happens when data got turns out to be even more a block as opposed to an assistance when the data is conceivably valuable. Clinical specialists have restricted opportunity to survey and handle persistent information, which may bring about mistakes during the data recovery and dynamic cycles. Potential impacts of data over-burden are as per the following: neglecting to deal with a portion of the sources of info, handling data mistakenly, postponing the 
preparing of data, tolerating lower-quality data and surrendering the quest for required data (Chapman, Berger, Weinstein, Weeks, Goldie and Neumann, 2004).

Incredible and amazing clinical dynamic requires a blend of contribution and aptitudes. According to (Nuq, 2012), these aptitudes join model affirmation which is picking up for a reality; essential thinking, wiping out inclination from speculation, being 'wary', with the ability to clarify goals, review notions, be open, see singular points of view and tendency, prepared to survey confirmation; social capacities, full focus the ability to check out the patient, what they state - what they don't express, their story, their experiences and their longings thus enabling a patient-centered strategy that grips self-organization; information course of action the ability to give information in an understandable way to allow patients/clients, their employments and family to be locked in with the dynamic cycle and evidence based methodologies, utilizing accessible proof and best practice rules as a feature of the dynamic cycle. Different aptitudes needed for compelling clinical dynamic as detailed by Nuq (2012) are cooperation, utilizing the accumulated proof to enroll help, backing and guidance from partners and the more extensive multi-disciplinary group. It is imperative to liaise with partners, tune in and be deferential, while additionally being determined when one requirements uphold so one can design as a group when fundamental; Sharing taking in and getting criticism from associates on your dynamic; reflection; utilizing input from others, and the results of the choices to consider the choices that were taken to improve practice conveyance later on. It is likewise significant for clinical specialists to think about their entire dynamic systems to guarantee that they sharpen their dynamic abilities and gain for a fact.

\subsection{Statement of the problem}

Clinical specialists' dynamic is a colossal undertaking that regularly requires clinical pioneers to gauge genuine compromises, think about patients' qualities, and join proof even with vulnerability. Clinical choices are settled on certainly by clinicians and other leaders consistently. Choices dependent on close to home experience are dependent upon numerous predispositions. Numerous choices that the wellbeing laborers make over the span of their day by day practice are important for routine clinical mind and include little idea, vulnerability, or danger. Be that as it may, choices should likewise be made in analytic or treatment predicaments for which there are no simple answers. Fusing proof, weighing troublesome compromises between expected advantages and hurts, and including patients' qualities for these results can be a perplexing test. Choice examination and cost-adequacy investigation are quantitative methods that give an efficient way to deal with coordinating proof inside the setting of a particular choice issue.

Clinical specialists engage in a range of activities related to the care and/or treatment of a patient and refer generally to the provision of a public sector health services that encompass diagnosing, maintaining, or treating the patient's physical or mental condition. During patient consultations and primary healthcare, the clinical specialists need patient-specific information. Getting to data in an opportune manner is fundamental for the clinical dynamic cycle. In the event that data needs stay unanswered at the time the clinical specialists are settling on clinical choices, at that point deferred or clueless choices may happen. Thusly, there might be clinical blunders, for example, erroneous finding, mistake in managing treatment or inability to give prophylactic treatment, which impacts the quality and result of choices. Clinical dynamic is an equilibrium of involvement, mindfulness, information and data gathering, utilizing proper appraisal apparatuses, partners and proof based practice to manage. Clinical specialists have most likely consistently realized that their choices have significant ramifications for quiet results. Progressively, in any case, they are being projected in the job of dynamic in medical services by strategy creators and different individuals from the medical care group. 
Clinical experts are depended upon to will, survey, and breaker research verification into their master judgment and clinical dynamic. Data assets are utilized by the clinical specialists to supplement their insight and clinical experience and to stay up with the latest. The adequacy and fundamental job of data availability and data use by effectively drew in clinical specialists for clinical dynamic can't be over underscored. The connection between the availability and utilization of wellbeing data from various sources and the choices to which such data is applied just as the relationship that exist between the choices that clinical specialists make and the information that educates them are worth given consideration. The assets that clinical specialists use in their everyday clinical dynamic is a significant subject to explore, consequently this examination.

\subsection{Research questions}

This research provided answers to the following questions:

1. What are the health information tools accessible for clinical decision making among clinical specialists in Obafemi Awolowo University Teaching Hospital (OAUTH), Ile-Ife, Osun State, Nigeria?

2. What is the level of accessibility of health information tools for clinical decision making among clinical specialists in OAUTH?

3. What is the frequency of accessibility to health information tools for clinical decision making among clinical specialists in OAUTH?

4. What is the extent of the use of various health information tools for clinical decision making among clinical specialists in OAUTH?

5. What is the frequency of use of health information tools for clinical decision making among clinical specialists in OAUTH?

6. What is the extent of use of various core skills of clinical decision making among clinical specialists of OAUTH?

7. What are the challenges impeding clinical specialists in the use of health information tools for clinical decision making in OAUTH?

\subsection{Objectives of the study}

The general objective of this work was to investigate the influence of access and use of health information tools on clinical decision making among clinical specialists in OAUTH. Other specific objectives the research set out to achieve were to:

1.identify various health information tools accessible for clinical decision making among clinical specialists in OAUTH.

2. determine the level of accessibility of health information tools for clinical decision making among clinical specialists in OAUTH.

3. examine the frequency of accessibility of health information tools for clinical decision making among clinical specialists in OAUTH.

4. determine the extent of use of various health information tools for clinical decision making among clinical specialists in OAUTH.

5. examine the frequency of use of health information tools for clinical decision making among clinical specialists in OAUTH.

6. investigate the extent of use of various core skills of clinical decision making among clinical specialists in OAUTH. 
7.investigate the challenges impeding clinical specialists in the use of health information tools for clinical decision making in OAUTH.

\subsection{Research hypotheses}

The following null hypotheses were tested at 0.05 level of significance:

$\mathrm{H}_{01}$ : There is no significant relationship between access to health information tools and clinical decision making among clinical specialists in OAUTH

$\mathrm{H}_{02}$ : There is no significant relationship between the use of health information tools and clinical decision making among clinical specialists in OAUTH

$\mathrm{H}_{03}$ :There is no significant joint contribution of access and use of health information tools to clinical decision making among clinical specialists in OAUTH

$\mathrm{H}_{\mathrm{o4}}$ : There is no significant relative contribution of access and use of health information tools to clinical decision making among clinical specialists in OAUTH

\subsection{Scope of the study}

This study focused on access, utilization of wellbeing data assets as indicators of clinical dynamic among clinical experts in Obafemi Awolowo University Teaching Hospital Osun State Nigeria. The reason for studying this University Teaching hospital was because of its age-long and federal status. OAUTH was one of the foremost university teaching hospitals that was established in Southwestern Nigeria. The population for this study consists of clinical specialists in Obafemi Awolowo University Teaching Hospital. The study examined clinical specialists who are core clinical decision makers. These are consultants, house officers, residents and supernumerary. It further examined the health information and clinical information accessible to and are used by them

\subsection{Significance of the study}

The significance of this study arises from the need to examine the level of accessibility and extent of use of health information tools as predictors of clinical decision making among clinical specialists in a teaching hospital in Nigeria. Knowing the most relevant information needs of clinical specialists can assist health information professionals to be better prepared with tools to assist clinical specialists with information searching. The study has also helped to confirm that clinical specialists needed access to job-specific information tools to satisfy their different information needs. The results of this study have shed light on the holistic understanding of medical doctor's information behaviour studies from multiple disciplines approach. The complete preview of this investigation has caused wellbeing data experts to expand their subject information past the current business as usual of library and data science discipline. Wellbeing data experts can apply their insight from multidiscipline to explore backing and data education guidelines to empower their customers to quickly get a handle on the refreshed examination. Furthermore, this examination has given proposals to future exploration on clinical specialist's data conduct on clinical dynamic. A scope of 
imaginative electronic data frameworks have been made to help assorted and developing parts of clinical specialists in the medical care framework like the accessibility of enormous informational collections, for example, medical clinic release information bases, imperative insights, and transferable infection records. These have for quite some time been gathered and utilized by government to set administrative approaches and screen general wellbeing. Thus, the aftereffects of this examination have helped the wellbeing framework administrative bodies and strategy producers to all the more likely see a few variables affecting proficient and successful clinical dynamic among the clinical specialists in Obafemi Awolowo University Teaching Hospital. This examination has additionally been of colossal commitment to the scholastic scientists in the field of wellbeing data as significant information exuding from the current truths was made accessible after exhaustive information investigations.

\subsection{Operational definition of terms}

The following terms were operationally defined in this study

Access to health information: alludes to the simplicity with which clinical specialists obtain the correct wellbeing data from accessible wellbeing data assets to take care of wellbeing related issues through clinical dynamic

Use of health information: is the application and utilization of data to address a person's issue

Health Information: are facts, news, symbols and database that can improve medical doctor's health information knowledge

Health Information tools : are those materials that can store information in any frame or permit information go through them. Wellbeing informatics assets incorporates data and correspondence innovation (ICT) gear and offices, for example, ECG machine, CT check, electronic BP measure, Radiograph, Hemoglobin electrophoresis, Centrifuge machine, Autoclave, Glucometer, Orthoscopic, Sphygmomanometer, Microscope GSM telephones, I-cushion, I-case and the web. Others are PC frameworks, CD-ROMs, VCDs, DVDs, scanners, Printers

Clinical decision making: refers to the expert or professional clinical decision arrived at by the medical doctor with a view to solving a particular health related problems or is as contextual, continuous, and evolving process, where data are gathered, interpreted, and evaluated in order to select an evidence-based choice of action

Medical doctor: A bunch of experts associated with a scope of exercises identified with the consideration as well as treatment of a patient. They are associated with giving wellbeing administrations, for example, diagnosing, keeping up, or treating the patient's physical or state of mind.

Teaching hospital: central government possessed tertiary wellbeing foundation set up to provide food for the wellbeing and general prosperity of the general population and is burdened with the obligation of preparing and retraining wellbeing and clinical related experts. 
Wellbeing data access and use is an exceptionally explored region in library and data sciences yet there are regions that have not gotten enough consideration. This is a result of the intricacy of human conduct, broadness of the zone of data conduct and consistent changes in the data administrations and the manner in which we utilize data for various parts of life. There have been advancements of various standards, hypotheses and models in wellbeing data conduct research throughout the only remaining century because of genuine examination. One of such investigated territories is the relationship that exists between the entrance and use as factor of wellbeing data conduct and clinical dynamic by clinical specialists in OAUTH.

\subsection{Clinical decision-making}

Decision making is an expansive term that applies to the way toward settling on a decision between alternatives with respect to a course of activities. Clinical dynamic by clinical specialist is a more unpredictable cycle, requiring a greater amount of people than settling on characterized decisions between restricted alternatives. Clinical specialists are needed to settle on choices with various foci (for example finding, mediation, communication and assessment), in unique settings, utilizing a different information base (counting an expanding assemblage of proof based writing), with numerous factors and people included. Also, clinical choices are described by circumstances of vulnerability where not all the data expected to make them is, or can be, known. In this setting of clinical dynamic there are only sometimes single choices produced using fixed decisions where one choice can be disengaged from others. The number and kinds of choices looked by clinical specialists are identified with the workplace, impression of their clinical job, operational self-rule, and how much they consider themselves to be dynamic and powerful chiefs. Clinical specialists chipping away at a bustling clinical confirmations unit conceding 50 patients for every day face an alternate arrangement of choice difficulties contrasted and wellbeing guests (HVs) or general wellbeing laborers, who may see 10 patients for each day. Think about the degree to which judgment and decisions include in this current HV's interview: Rather, choices are installed in choice activity cycles where circumstances develop and where choices and activities impact one another.

A choice issue is basically portrayed by task factors (for example time pressure, the quantity of choices, or the plenty of data portraying those other options) and setting factors (Pfeiffer and Johnson, Gimbel-sherr 2004). Medical services dynamic settings as a circumstance where issues are not well organized and made equivocal by the presence of inadequate powerful data and various connecting objectives. The dynamic climate is dubious and may change while choices are being made. Objectives might be moving, poorly characterized or contending. Dynamic happens as activity input circles, where activities bring about impacts and produce additional data that chiefs need to respond to and use to settle on additional choices. Choices contain components of time pressure, individual pressure and profoundly huge results for the members, numerous players demonstration along with various jobs in hierarchical objectives and standards impact dynamic.

Clinical decision has customarily elaborate a cycle of individual medical services specialists settling on choices in the interest of patients. Chapman (2004) named this proxy dynamic. All the more as of late, accentuation has been set on clinical dynamic as a cooperative cycle, including shared and equal dynamic with patients and groups of wellbeing laborers (Edwards, Jones, Higgs, 2004).

The community idea of dynamic implies that any thought of variables impacting professionals' clinical dynamic could likewise consider factors affecting group dynamic and patient dynamic. 
Given the multidimensional and complex nature of clinical dynamic, factors affecting it might emerge from various sources, bringing about contrasting impacts for various people. Dynamic about individual patient consideration is a complex and logically subordinate cycle in which dynamic comprises of a center cycle where choices are made about patients' medical services issues, fitting remedial intercessions, and ideal methods of collaboration and strategies for assessment heaps of the undertaking, for example, trouble, unpredictability and vulnerability. Dynamic includes a dynamic, complementary cycle of drawing in with situational factors in the quick setting encompassing the choice to distinguish and utilize these variables in settling on choices and doing an ideal strategy, and, simultaneously, dealing with the impact of these elements on dynamic to encourage accomplishment of an ideal game-plan professional elements, (for example, their casings of reference, singular abilities and experience of physiotherapy dynamic in the significant work settings) impact the choices they make.

Decision is arranged inside a more extensive logical ethos, with measurements specific to the training in the particular work environment. Navigating these components, to oversee and sort out them requires four key capacities: psychological, enthusiastic, social and reflexive (Smith, Higgs and Ellis, 2010). The undertaking of dynamic is to settle on activity related decisions. Choices can be characterized as far as characteristics, for example, dependability, assurance, commonality, criticalness, consistency, danger, and pertinence and number of factors (Connolly, Arkes, Hammond, 2000, Eraut 2004, Whitney 2003). In each clinical practice circumstance choices are described by an interesting mix of these properties. Past examination indicated that singular choice ascribes have posts of trouble battling with stable versus unsteady, recognizable versus new, with additional trouble and multifaceted nature emerging from the summation and interchange between credits (Smith 2006).

Evaluated writing uncovered that choices were more troublesome if there was vulnerability, strife, newness, evolving conditions, various important factors, and high danger. Troublesome choices had a moral and enthusiastic measurement that the members discovered testing while commonality, conviction, restricted factors, soundness, consistency, and generally safe are ascribes that settled on a choice moderately basic. People embrace distinctive dynamic cycles, for example,

Authors Uniqueness: which is the degree to which the highlights of this choice are not normal for different choices. For instance, uniqueness in settling on choices about issues identifies with the exceptional highlights of this patient and their condition in this particular setting (Coulthard 2007).

Certainty: The amount of information and clear guidelines that exist as to the interpretation of data and to guide a course of action (Whitney, 2003)

Importance/criticalness/value conflict: The noteworthiness of the choice corresponding to result and impacts of negative outcomes. Criticalness is utilized interchangeably here to identify with the degree to which the result of the choice is of high significance as for result or where there is the high potential for a negative result (Whitney, 2003)

Stability: The degree and rate at which the climate encompassing the choice is changing or developing. For instance, an unsteady choice climate is the place where the patient's ailment is changing at the time the choice is changing with the end goal that new information are being gotten and deciphered requiring a dynamic cycle (Whitney 2003)

Urgency: The extent to which an immediate decision needs to be made or whether it can be delayed (Smith, 2006).

Familiarity: The extent to which the decision being made is similar to decisions made in the past (May, 2003)

Congruence/conflict: The extent to which elements of the decision such as the inputs, goals, and environment of the decision fit, match and correspond with each other (Lewis, 2003). 
Number of variables: The amount of data that need to be considered and interpreted in order to make a decision (Lewis, 2003, Brandon and Hollingshead 2004).

Relevance of variables: The degree to which the information accessible contain data pertinent to the choice being made that should be arranged from insignificant material (Lewis, 2003).

Risk: The assessment of the possibility of an unfavorable or negative result happening because of the choice Smith (2006) as per choice credits (Eraut 2004). Such contrasts in dynamic are communicated in the sorts of thinking approach utilized in dynamic and the speed of dynamic. With less time, more quick reactions and less insightful methodologies are embraced (Eraut 2004).

Cognitive continuum theory (CCT) is a hypothesis of judgment and dynamic that joins methods of discernment to highlights of the errand (Hammond 2000). The hypothesis to clinical dynamic, utilizing a continuum of discernment from instinct to investigation, with methods of cognizance happening in the middle of that utilization a mix of the two methodologies. Undertakings that initiate (more slow) scientific methodologies are all around organized, equipped for being separated into areas, and present with complete data. Then again, when assignments are ineffectively organized and are high in degree of vulnerability there is little to examine and along these lines the best methodology is one that attracts on instinct to coordinate material (Paterson and Higgs 2001).

These hypothetical viewpoints are reflected in other examination attempted in clinical settings, with highlights of dynamic, for example, absence of commonality and vulnerability easing back clinical specialists' dynamic cycles (Bucknall 2003). We additionally found that, when settling on choices in intense consideration settings, members reacted to basic choices by picking a standard method of work on, picking a mediation that they discovered generally worked, and changing their decision to fit the exceptional circumstance by embracing more inventive and novel ways to deal with intercession. Conversely, when choices were troublesome, members were bound to test, draw upon the information on others, weigh up the contending parts of the choice and observe conventions or rules, looking for less open door for innovativeness.

Essentially, Ewing and Smith (2001) found that wellbeing laborers confronted with complex undertakings utilized shrewd arranging rather than a precise methodology. They noticed that they received a methodology reliable with a natural methodology, where they sought after whatever appear to be advantageous or promising at that point. Dynamic is impacted by how people conceptualize the choice to be made and the result they try to accomplish. A supposition in clinical practice is that people settle on choices with the point of settling on the most ideal decision, this being to pick the correct determination, or to upgrade quiet results if the choice is picking an intercession. This supposition might be a speculation, with medical care experts conceivably outlining the ideal results of their dynamic on the other hand.

Various variables will be significant, contingent upon a chief's psychological portrayal of the circumstance (Soman 2004). The outlining of wanted results in these various manners has significant ramifications for dynamic. Though one individual may see the objective of dynamic as accomplishing an ideal result and is set up to face a challenge to do as such, another might consider the to be objective as security and be considerably less liable to face a challenge. (Schiliro 2012) utilized the term choice edge to allude to the leader's origination of the demonstrations, results, and possibilities related with a specific decision. They recommended that the casing a chief receives is controlled halfway by the plan of the issue and somewhat by the standards, propensities, and individual qualities of the leader. Given this point of view, clinical dynamic will be influenced by the standards and propensities which chiefs have gained through their experience of clinical practice.

\subsubsection{The core skills of clinical decision making}

Great, viable clinical dynamic requires a mix of involvement and abilities. These aptitudes include: Pattern acknowledgment which is gaining as a matter of fact, basic Thinking: eliminating feeling from our thinking, being suspicious, with the capacity to explain objectives, inspect presumptions, be receptive, perceive 
individual perspectives and predisposition, ready to assess proof, relational abilities: undivided attention the capacity to tune into the patient, what they state - what they don't express, their story, their experiences and their cravings therefore enabling a patient-centered approach that grips self-organization; information game plan - the ability to give information in a possible way to allow patients/clients, their contemplations and family to be related with the dynamic cycle, evidence based philosophies: using available confirmation and best practice rules as a part of the dynamic cycle, cooperation: utilizing the accumulated proof to enroll help, backing and counsel from partners and the more extensive multi-disciplinary group. It's essential to liaise with associates, tune in and be deferential, while likewise being relentless when you need uphold so you can design as a group when important, sharing: ones taking in and getting criticism from partners on one's dynamic, reflection: utilizing input from others, and the results of the choices to ponder the choices that were taken to improve practice conveyance later on. It's likewise critical to ponder your entire dynamic methodologies to guarantee that you sharpen your dynamic abilities and gain for a fact.

\subsubsection{Factors impacting clinical specialists' clinical decision making}

The method of dynamic is expected to shift across a continuum as the dynamic depend on some relevant variables which characterized by how all around organized or poorly organized the assignment is. In the event that a choice undertaking is very much organized, at that point orderly thinking will prompt the best choices, while sick - organized assignments are most appropriate for instinct (as does the structure of an errand) and accordingly carries goal to the contradicting hypotheses of choice. Among the elements that sway wellbeing laborers' clinical dynamic incorporate and not restricted to: Individual factors, for example, age and instructive Level: Some of the most investigated, components of clinical choice - making are age and instructive level, probably on the grounds that the information are anything but difficult to gather and simple to use as factual covariates. One possible purpose behind this is that reviews utilize a coarse proportion of training (contrasting clinical specialists and just secondary school confirmations to any remaining degrees of instruction) and along these lines struggle recognizing contrasts. Another explanation may be on the grounds that numerous examinations utilize specially appointed ward factors, for example, topics that rise out of meeting records. In any case, there isn't sufficient reliable proof to expect to be that instructive level or age affects clinical dynamic, experience, information, and prompt acknowledgment. Precise choices can't be reached without some degree of information it is the establishment of dynamic. Information enables clinical specialists to recognize data prompts identifying with the choice issue. On the off chance that clinical specialists' information base is restricted or disabled, less choice signs will be perceived and choices will be founded on incomplete data prompting less fortunate choices. Clinical experience adds to the viable and useful information that clinical specialists need to settle on complex choices. Be that as it may, amateur clinical specialists have practically no involvement with clinical settings. This represents a few impediments on their overall capacity to perceive applicable data signs identifying with the choice, theory refreshing: Expert wellbeing laborers have been appeared to utilize an expansive way to deal with dynamic (Corcoran, 2009). They structure general speculations and afterward refresh and refine them while getting new data prompts. Paradoxically, learners utilize a more engaged methodology and quickly structure explicit speculations. They at that point experience difficulty refreshing their unique speculation while accepting new data, which can prompt choice mistakes (Hammond 2000). Which incorporate correspondence: One technique to accumulate extra data signs is to talk with the companion nursing staff (Hedberg, and Larsson, 2003). This is particularly significant for complex choices where another viewpoint may offer some knowledge. Correspondence encourages sign procurement and is a need for social affair data from patients. Nonetheless, fledglings are unconfident in their correspondence capacities and battle to impart in the basic regions of nursing (Casey, Fink, Krugman, and Propst, 2004). This expansion the danger of settling on choice mistakes, feelings and insights: A clinical specialists' present status of feeling will influence their choice - making capacities. A certain clinical specialist will be more self-assured in their choice - making and this permits them to assume responsibility for 
circumstances. On the other hand, a clinical specialist who isn't sure will have self uncertainty in their choices, feel weak, and be uncertain of their decisions. Proactive dynamic is likewise connected with certainty. Sure wellbeing laborers were initiators and settled on protection choices as opposed to just reacting to issues (Hagbaghery, Salsali, and Ahmadi, 2004), natural components task intricacy: The most hearty ecological factor of clinical dynamic is the unpredictability of the choice errand (Lewis, 2001). Intricacy can include quite a few factors that expansion the intellectual burden on the leader. The most well-known controls are the quantity of excess prompts, repudiating signals, prompts that demonstrate either certain or negative changes, or expanding the quantity of unessential signals. Exactly, choice quality is appeared to endure when intricacy is expanded (Hughes, Bruke and Hanson 2008), time pressure: Another vigorous natural factor that disables clinical choice - making is time pressure. Thompson, Bevan, Sparks (2012) had Health Workers settle on choices about mediations either under no time imperatives or under time tension. Clinical specialists with more experience settled on better choices when they were selfguided however presenting time pressure killed this preferred position and all clinical specialists performed inadequately. In the nursing practice, time weights can be found in numerous structures. For instance, fledglings feel strain to finish their rounds and leave a spotless sheet for the approaching clinical specialists. This presents a deliberate time pressure, which can bargain their dynamic like: Interruptions: Interrupting the choice - making measure puts extra intellectual strain on the chief by compelling them to deal with data that is generally superfluous to the current undertaking. The contending data dislodges memory substance, some of which is significant and applicable to the choice. Notwithstanding, this doesn't really prompt more unfortunate choices, in essence. Just when intellectual requests outperform the leader's psychological limit will choice exactness endure and zone of forte and expert independence: Decision assignments are not comparable in all nursing offices and units. They contrast on numerous measurements, for example, normal assignment intricacy, time pressure, or the quantity of supporting clinical specialists. This outcomes in inconsistent choice blunder base rates across the zones of nursing claims to fame. Also, proficient independence the opportunity to settle on choice can vary across divisions. Independent clinical specialists have been appeared to settle on preferred quality choices over wellbeing laborers who are less self-ruling (Bakalis, Bowman, and Porock, 2003). Independence permits wellbeing laborers to put more noteworthy spotlight on patients, which encourages dynamic

\subsection{Health data assets for clinical dynamic}

Health information tools underpin dynamic in wellbeing strategy, the executives and clinical consideration through the assortment, normalization, coding and the board of data applicable to pointers of wellbeing status, determinants of wellbeing, clinical choice help (CDS) gives clinicians, staff, patients or others with information and individual explicit data, wisely separated or introduced at fitting occasions, to improve wellbeing and medical services. Albums includes an assortment of devices to improve dynamic in the clinical work process. These devices incorporate mechanized cautions and suggestions to mind suppliers and patients; clinical rules; condition-explicit request sets; centered patient information reports and outlines; documentation formats; indicative help, and logically important reference data, among different devices. Wellbeing data advances intended to improve clinical dynamic are especially appealing for their capacity to address the developing data over-burden clinicians face, and to give a stage to coordinating proof based information into care conveyance. Most of CDS applications work as parts of extensive EHR frameworks, in spite of the fact that independent CDS frameworks are additionally utilized. The principle motivation behind CDS is to give convenient data to clinicians, patients, and others to illuminate choices about medical care. Instances of CDS instruments incorporate request sets made for conditions or kinds of patients, proposals, and data sets that can give data pertinent to specific patients, updates for preventive consideration, and alarms about possibly perilous circumstances. Albums can possibly bring down expenses, improve effectiveness, and diminish tolerant burden. Indeed, CDS can now and then address each 
of the three of these territories simultaneously for instance, by alarming clinicians about conceivable copy tests a patient might be going to get.

Wellbeing data incorporates data for sound living, forestalling and overseeing infections, settling on choices about wellbeing items and wellbeing administrations and settling on different choices identified with wellbeing and medical services. It very well might be as information, text, sound, video, additionally recognized that the web for wellbeing data: looking straightforwardly for wellbeing data; partaking in care groups/social web stages and talking with wellbeing experts. Wellbeing data through the web has the upside of being custom-made to singular wellbeing needs and here and there to network wellbeing needs which might be hard to get to. It eliminates geological and actual obstructions in getting to wellbeing data. Because of the secrecy of the web, it takes into consideration the entrance of touchy and humiliating wellbeing data and diminishes demonization of patients. The web gives the accommodation to proficient online mediation frameworks with coordinated wellbeing and clinical data on decisional backing, questions and replies, and online collaboration, a discussion for communication with wellbeing proficient specialists or other framework clients. Through web-based media, the web gives different stages to patients with indistinguishable foundations and wellbeing worries to divide worries between themselves and among online care groups for passionate help, the nature of wellbeing data got to through the web isn't in every case great. With huge amount of site pages, online administrations and applications identified with wellbeing, there are worries over the nature of wellbeing data, discovered that over $70 \%$ of wellbeing related sites have low quality of wellbeing data got to on the web. Indeed, even the appealing plan of certain sites may give an off-base impression of the nature of the site

\subsection{Relevance of health information to the medical doctor for clinical decision-making}

Data is a fundamental piece of all aspects of life and its essential job is tremendous. Data is power. It is a significant crude material and its procurement and comprehension is pertinent in dynamic, arrangement detailing, just as usage for development and endurance. Precise and opportune data is fundamental any place a choice should be taken or issues must be addressed. It is therefore imperatively important that individuals get appropriate information at the appropriate time. The absence of information will make it difficult for individuals to exploit and utilise the tools and service available. However, the term information has been severally defined and used to identify several concepts. Based on these identified likely factors, there may never be a generally accepted definition. Information can, however, be defined as facts, opinions, ideas, from any source that would aid in making adequate decisions (Folorunsho and Haruna 2005). Williams and Roseline (2009) corroborates Fonkych and Taylor (2003) view by identifying information as one basic resource required for the improvement of life. Those who possess appropriate and timely information are more likely to make rational decisions than those who do not.

This indicated by Islam and Ahmed (2012), cultural necessities are fulfilled through different sorts of exercises, every one of which require data as an information. These incorporate, for instance, schooling, strategy definition, exploration, and improvement, individual necessities, business, dynamic, mass correspondence, public and private products. Cultural requirements are additionally fulfilled at various levels, from people through worldwide networks with data. Accordingly, it tends to be said that data, if all around bundled, will annihilate destitution, limit obliviousness and give edification on the best way to accomplish, social, instructive, political and social goals towards the advancement of the whole society. Bigdeli and Javadi (2013) sees that data is vital for quick turn of events and assumes an essential part in the endurance of people and countries. Data empowers individuals to adapt to the issues of regular daily existence and improve human relationship in the network, particularly among individuals of various societies and conventions, consequently 
adding to better arrangement and world collaboration. Data assumes a significant job in every human action, and its incentive in the advancement cycle has been a subject of broad discussion. It has been seen that approaching the correct sort of data can address the serious issues of obliviousness and destitution that can thwart the strengthening of people. A modest bunch of creators (Bell and Chapman 2001) thought that absence of data can influence the strengthening cycle contrarily, however it is as yet not saw as being as significant as different assets. Thus, data can be viewed as a fundamental asset for networks, the whole people (jail prisoners comprehensive) to improve their everyday environments. It is a basic asset since it doesn't just extend the potential outcomes of social, political, instructive, and monetary improvement of any nation, yet it likewise encourages mindfulness and strengthening (Islam and Ahmed 2012).

Dependable data is the foundation for building the mindfulness ability and functional systems important to improve the world we live regarding wellbeing, physical, specialized, mental, social, and logical advancement of humankind (Onajite 2015). It along these lines follows that accessibility, availability and usage of data will manage the cost of the jail prisoners the occasion to be enough mindful of the chances of meeting their data needs for their sociopsychological prosperity. Anderson, Panos and Spencher (2004) states that admittance to data is a fundamental condition for improvement and strengthening. Consequently, it tends to be said that data, if all around bundled, will destroy destitution, limit obliviousness, and give illumination on the most proficient method to accomplish social, instructive, political, and social targets towards the advancement of the whole society. Kajtazi (2012) believed that data is vital to the improvement of people, social orders, and countries and that absence of or insufficiency of its official acknowledgment (powerlessness to remember it as a public asset) in the non-industrial countries can scarcely get away from the consideration of the data trained professionals. Today, data is imagined as a significant asset that contributes fundamentally towards the improvement of individual; jail detainees comprehensive, particularly in this period of data blast. Information provides the main stay for the development of knowledge, the foundation for innovations, and the tools for an informed citizenry, and as a result, it becomes a key commodity for the progress of any society. Fox (2003) states that, those that are well informed are able to respond positively and appropriately to the demand of their environment. Information also strengthens their social networks. At this junction, it can be said that information, if well-articulated, could eradicate ignorance and provide enlightenment on how to achieve economic, educational, social, political, personal, cultural objectives and social-psychological wellbeing Samson, Alarape, and Aramide (2015) and Limberg, Sundin and Talja (2012) opines that the least expensive input of human development and empowerment is information. This supports the relevance of the information revolution. Information therefore is seen as a super ingredient for self-reliance, social and economic changes and development of an individual, business, corporate body, and nation. Since information is no longer the prerogative of free citizens only, it therefore follows that with adequate, reliable, complete, and accurate information, clinical specialists can overcome most of the challenges and problems confronting them in their everyday clinical dynamic

\subsection{Sources of health information to clinical specialists for clinical decision making}

Current writing recommends that specific wellsprings of data are utilized in changing degrees among the Medical specialists and thusly the particular classes of wellbeing data sources reached make some clinical 
specialists more powerful than others in clinical dynamic. Wellbeing correspondence is a way to deal with pass on data with the objective of improving wellbeing results by empowering conduct adjustment and social change through the continuum of information, convictions and perspectives, and practices, (Schiavo, 2007). Wellbeing correspondence procedures using broad communications (e.g., T. V, print and web) have been a related with wellbeing convictions and practices (Hag, Coups, Ford and DiBonaventura 2009; DuttaBergman 2004). More recently, the influence of social networks (i.e, the web of social relationships that surround an individual tied by a type of interdependency, such as friendship, kinship, or vocation/interests) on various aspects of health has been studied (Christakis and Fowler 2007). These interpersonal relationships, either those made through social ties such as friends/family or community organisations or those with healthcare providers may also be sources of health information and have been associated with health beliefs and possibly behaviours.

Not many examinations have looked at the qualities of relationship of classes of wellbeing data sources (i.e, broad communications versus relational) with infection counteraction and screening practices. Since specific wellsprings of data are utilized in fluctuating degrees among various financial and segment gatherings, (Christakis and Fowler 2007), it is essential to decide whether explicit classes of wellbeing data sources are more powerful than others in advancing wellbeing practices. It was guessed that relational sources, including both lay informal communities (loved ones and network associations) and medical services suppliers, would be all the more emphatically connected with wanted wellbeing practices because of their capability to give data as well as social backings. Variability in clinical decision making may result from the use of diverse information sources to guide clinical decision making. In routine clinical decision making, clinical specialists information sources are classified into two broad group thus: Broad communications Sources (print, TV and web) and relational sources (social networks), community organisations friends and family. Print media like newspaper or of a general magazine seldom provide health sections of the newspaper or magazine may provide a useful information that can aid effective clinical decisions. How many community organisations one is currently a member and the extent to which these community organisation(s) provide data on wellbeing

Loved ones: Do you have companions or relatives that you converse with about your wellbeing? How habitually do you converse with these companions or relatives about wellbeing?

Television: Some local television news programs include special segments of their newscasts that focus on health issues. How often Health workers watched health segments on local news can determine the use of such source of information.

Decision making theories suggest a common set of cognitive skills implying that decisions are generally considered in the same way, regardless of the person or situation (Hastie and Dawes 2010). Although studies have addressed decision making, Spenceley, Leary, Chizawsky Ross and Estabrooks (2008) conducted a meta-analysis to assess the types of information used by qualified health workers to inform their practice. The most highly relied upon the sources of information were from other health workers and peers disseminating evidence. In contrast to health workers in many other studies who tended to privilege evidence derived from work--based activities, such as clinical experience or from interaction with senior nursing or medical colleagues (Gerrish, Ashworth, Lacey and Bailey 2008; Spenceley et al., 2008; Jansson and Forsberg 2016) in the sense study drew on an assortment of wellsprings of proof.

Formal instructive projects and proceeding with proficient improvement openings (study days/meetings) were key wellsprings of proof for this examination. Current writing recommends that specific wellsprings of data are utilized in fluctuating degrees among the clinical specialists and hence the particular classes of wellbeing data sources reached make some clinical specialists more compelling than others in clinical dynamic. Wellbeing correspondence is a way to deal with pass on data with the objective of improving wellbeing results by empowering conduct alteration and social change through the continuum of 
information, convictions and perspectives, and practices (Schiavo, 2007). Wellbeing correspondence systems using broad communications, for example, TV, print, and web have been related with wellbeing convictions and practices (Hay, Coup, Ford, DiBonaventura 2009, Dutta-Bergman 2004,).

All the more as of late, the impact of informal organizations the snare of social connections that encompass an individual tied by a kind of interdependency, for example, kinship, family relationship, or job/interests on different parts of wellbeing has been considered (Christakis, Fowler, 2007).

\subsection{Health information access for clinical deynamics among Clinical specialists}

Health Information accessibility refers to the ease with which clinical specialists acquire the right information from available sources to solve the problems encountered during clinical decision making (Kahane 2011). Accessibility to health information is seen in relation to nearness, ease of use and opportunities for interaction with people and other agencies while proximity and physical distance to a source or channel have been found to be factors influencing use of information. Aguolu and Aguolu (2002) uncover that endeavors are being made worldwide to elevate admittance to data. They anyway regret the orderly highlights of underdevelopment, for example, power disappointment, machine breakdowns, and absence of extra parts and specialists, which discontinuously slow down the presentation of current devices of data stockpiling and move in non-industrial nations.Oltman (2009) provided an early example of the difficulties in articulating information accessibility. He identifies six components of information access, which are identification, availability, price (to the users), cost (to the provider), understanding (awareness), and acceptability. Similarly, Gans, Kralweki, Hammons and Dowd (2005) presents four elements of information accessibility, which are channel, nearness, and cost and literacy level. Yogarajan, Mayo and Pfahringer (2018) opines that an information channel serves as an intermediary, which guides or is supposed to guide an individual to a source. Channels/sources of information such as personal (colleagues and experts), impersonals (newspaper, registers and other print materials) does not exclude individual himself and technical communication media such as telephone, radio, video and internet. Gans, Kralweki, Hammons and Dowd (2005) affirmed that channel of information involves the interchange of facts and thoughts. Information must be transmitted by means of communication process before it can be accessed or used. Information nearness refers to the short distance or interval in information sources, which constitute an important factor for its accessibility. It explains the closeness of relationship between the source and information users (Davies 2007). Gatero (2010) also asserts that, information nearness is the distance or intensity and frequency of information interaction between the sources and the users. Thus, distance of information for a given source varies and is infinite (Choudhry, Fletcher and Soumerai 2005). When nearness is defined in terms of zero distance within the information and farness in terms of infinite distance outside it, what the users have left is a shift from proximity to access information. Basically, nearness in information is constituted on the basis of users recognising other sources that users can only acknowledge and access other sources of information when it is nearer than other sources. Information however is nearness to anybody in need of it due to technology and worldwide information for all project which aims at eliminating all the barriers to information accessibility. The peculiar condition of health condition may deprive patients' access to some sources of information for the purpose of health condition while health authority needs to establish and meticulously guide some sources of information for security purposes.

Cost of information has been identified as one of the major factors that hindered users' access to information (Panahi 2014). The cost of information before a user can obtain access varies depending on the source the information emerges from. For instance, some information sources are confidential and cost implication of accessing such information may influence the user to seek such information further. Chinnock, Nandi and Clarke (2005) buttressed this assertion when they said that high logistical cost of moving to the location where the information is situated is another crucial factor that determines information accessibility. There are various expenses for clients in acquiring admittance to data. These 
make more deterrents to data openness by the patients. Proficiency, which is characterized by (OED 2003) as the people's capacity to peruse and compose; an individual's office with or information about a specific theme (Aramide, Oduroye and Alagbe 2013). They further believe that proficiency level of data clients depend on clients' capacity to work in a specific setting that requires some foundation information about data. Jacobs, Amuta and Jeon (2017) reason that proficiency level influences the attitudinal and standards of conduct of people. This infers that clients with high education level can peruse, comprehend and follow up on any data got while clients with restricted proficiency aptitudes are probably going to have issues in deciphering the substance of data materials (Watts and Ibegbulam 2006). Aspinall, Good, Glassman and Valentino (2008) reasons that proficiency incorporates the capacity to peruse, however the multifaceted nature of data comprehended, got to and followed up on. The methods for admittance to data is an amazing procedural measure, which clinical specialists needs to build up and fastidiously guided for security purposes. This is so on the grounds that utilizing and holding just one methods for admittance to data can detrimentally affect the nature of data got to and this quality has an immediate bearing on the data to be gotten to and in like manner on the clinical dynamic. The term strengthening implies or could mean the way toward getting essential open doors for minimized individuals, either straightforwardly by those individuals, or through the assistance of non-underestimated concerned individuals who share their own admittance to these cycle (Afolayan and Oyekunle 2014). Be that as it may, specialists have distinguished different deterrents to data access. Panahi (2014) recognizes four hindrances to data access: financial, social, ecological, and foundation. This examination will talk about impediments in the accompanying zones: Social deterrent and non-accessibility of data. Social hindrance to patients data chasing and use may block the availability of wellbeing data. An effective openness of data relies on the accessibility of data and level of availability. Data ought not be founded on their degree of accessibility yet simple openness; it should be actually available to the individuals who need them. Openness of wellbeing data has directed concentration toward the issues looked by patients. Viable clinical dynamic relies upon data access framework offices like data innovation, web offices, continuous force supply, high education level that will encourage simple access.

\subsection{Health information use for clinical decision making among clinical specialists}

Scientists can just theory about the conceivable necessities of wellbeing laborers dependent on what they state, what we can deduct from viewing their conduct, or ideally both. Need can't be isolated from the intentions of data looking for conduct. In the event that a data need is to be changed over energetically, at that point people should have an intention in doing as such. In creating intentions, people draw on close to home structures of convictions and qualities, which contain objects that have fulfilled data needs before. For advocates of proof based dynamic, the essential thought process in drawing in with research based data is to lessen clinical vulnerability; that is, finding important exploration will build one's assurance that a specific strategy is well on the way to prompt the ideal results (Sackett, Sharon, Richardson, William and Haunes 2000). Notwithstanding, new data can likewise explain and additionally affirm existing data, convictions, and qualities. Wellbeing laborers regularly report that their reasoning for looking for research proof is to help their current practice. The cycles of looking for, evaluating, and coordinating exploration data with existing information have been named data conduct by certain scientists in the field of data science (Case, 2002). The kinds of clinical choices that wellbeing laborers really make give hints about how (and what sorts of) research data may aid dynamic. Different creators have inspected the clinical choices of medical care experts (and the clinical inquiries emerging from such choices) as articulations of potential data need (Cogdill, 2003). Consequently, choices are a significant setting for data use. It is practical to show how understanding the structure and attributes of the choices wellbeing laborers face is significant for understanding the manners by which data is gotten to and prepared by wellbeing laborers. Inclination for people as data sources both essential and intense consideration for clinical dynamic is 
decreed to be the main wellspring of data. Thompson, McCaughey, Cullum, (2004) reasoned that wellbeing laborers were portrayed by dependence on human wellsprings of data as the essential methods for advising circumstances in which they were unsure. Thompson, Bevan, Sparks (2012), distinguished particular points of view on availability, all of which stress the general openness of experiential wellsprings of data, for example, clinical wellbeing laborers trained professionals (CNSs), experienced associates, and other essential and auxiliary consideration group partners. Remarkable exemptions were neighborhood conventions and rules in intense consideration especially in territories, for example, the psychological continuum. Griffiths, (2010) affirmed that in any event, when literary data was viewed as open, human wellsprings of data were profoundly appraised regarding their openness. They likewise found that basic segment or historical factors, for example, clinical experience, instructive fulfillment, or part on the essential consideration group, were feeble indicators of viewpoints of available data sources. It is inappropriate to deduce, in any case, that examination based information has no part in clinical specialists' dynamic. Or maybe, clinical specialists decided not to utilize the deliberate inquiry evaluate actualize pattern of proof based dynamic progressively for genuine clinical choices with fast suggested reaction times. Wellbeing laborers got to prove based data sources on the off chance that they got to them at all in settings other than quick dynamic conditions. Clinical specialists portrayed contact with research-based data sources with regards to proceeding with proficient turn of events and formal instruction or preparing. Different impacts included being associated with the creation of nearby conventions and rules and figuring out exploration, for example, clinical preliminaries or utilizing research proof to help settle struggle between partners. Insights about the overall availability of human wellsprings of data were reflected when we got some information about the handiness of various wellsprings of data for clinical dynamic. Valuable data sources are grounded in clinical reality. Similarly as with openness, looked into writing recognized a few significant points of view on the overall value of various wellsprings of data for clinical dynamic. Every one of these points of view focused on the helpfulness of sources that depended on experience instead of exploration. Associates, different individuals from the essential consideration group, or senior individuals from the clinical group were seen as the most valuable (and open) data sources. Sackett et al., (2000) reasoned that segment and biographic factors, for example, age, clinical experience, and levels of instructive achievement, were helpless indicators of how valuable a data source would be to the wellbeing laborers

\subsection{Influence of health Information access and use on clinical specialists' clinical decision-making}

Clinical specialist are confronted with numerous clinical choices of changing intricacy in their regular practice. The vast majority of these choices spin around inquiries on the determination and restorative administration of patients. The recurrence of clinical inquiries fluctuates from 0.16 to 1.27 per tolerant relying upon claim to fame, and up to 5 inquiries in the inpatient setting, (Marcelo and Jimena 2013). During the time spent dynamic, doctors for the most part utilize their gathered clinical information, characterized as a doctor's very own insight base collected through long stretches of formal instruction, clinical preparing, research and clinical experience, (Charles, Sarminento, Gavino and Fontelo 2014) to address clinical inquiries. PGathered clinical information is generally utilized by doctors as it is the most helpful asset of data in the medical care setting. This is particularly featured in basic circumstances, for example, the crisis division where there might be a quick requirement for a determination and the executives. Notwithstanding, dependence on this information alone may prompt clinical mistakes when these clinical inquiries stay unanswered or unsupported by later clinical writing.

More clinical specialist are incorporating proof based medication in their clinical practice. Notwithstanding, doctors are confronted with various difficulties that forestall the usage of clinical 
choice emotionally supportive networks (CDSS), which are data frameworks intended to aid clinical choices by giving cautions, notices, and connections to significant data customized to patients, and the more extensive utilization of online proof based writing. Absence of time supposedly is one of significant reasons that keep doctors from getting to online writing to address their clinical inquiries. In a past report, $60 \%$ of doctors communicated that time was an issue in looking for data while in another examination, $40 \%$ of clinical inquiries stayed uncertain due to time imperatives (Ellis and Sharp, 2005) Another block that might be natural for the clinical calling is trust in their own clinical information. Doctors who don't see the need to get to data when confronted with a clinical inquiry, may blunder in their clinical choice. A few scientists recommended that the humanism of being a clinical expert, which holds doctors that have master information and clinical capability in high respect, may clarify this conduct (Timmermans and mauck 2005). The demonstration and view of expecting to look for information may ponder contrarily a doctor's capability and polished methodology (Kelley, Su amd Britigan 2015). In our comprehension of psychological cycles that muddle how doctors show up at their choices, we can see the job of trust in clinical thinking and data looking for conduct. Clinical specialists who accept that their amassed clinical information is all they require to arrive at a right choice won't be roused to get to outside assets and may conceivably be resolute to change an arranged administration course when data in the EBM writing that might be in opposition to their conviction is introduced (Samuel, Wolf and Wagner 2010). Friedman and Jeremy (2005) who originally endeavored to look at the connection among certainty and clinical determination precision, proposed four conditions of concordance or conflict that rely upon the arrangement of certainty and rightness.

In conditions of concordance, doctors who are sure about their choice are without a doubt demonstrated right in their patient administration. On the other hand, the individuals who are shy, or are not certain, and are wrong are additionally in a condition of concordance. Doctors who fall in both of these two conditions of concordance show suitable certainty and their convictions line up with the real world. The ideal circumstance would be doctors who are fittingly sure, while the individuals who are suitably reserved are probably going to be responsive to getting to outer wellsprings of data. Conversely, conditions of dissonance can be perceived as under certainty and presumptuousness. Doctors who are not certain but rather are right in their clinical choices are considered under sure. Doctors in this state are bound to look for data to affirm their choices, notwithstanding, it is as yet conceivable that doing so may guide them away from their initially right answer. (Friedman and Jeremy 2005). The condition of harshness that is of most prominent concern is arrogance. Doctors in this classification are sure about their clinical choices however truly, are inaccurate and are along these lines inclined to submitting clinical mistakes. These doctors are more averse to seek after extra data that could address their imperfect choice A ceaselessly learning wellbeing framework is driven by the consistent and fast age, preparing, and functional utilization of the best accessible proof for the condition. To accomplish such a framework, powerful and convenient methodologies for dealing with the steadily extending and complex cluster of clinical information and individual explicit information are basic for quickening routine ID and conveyance of the best accessible proof to the point of decision by wellbeing laborers for successful clinical dynamic. However our present medical services framework misses the mark concerning both the need and the potential in this regard. As the Charter of the National Academy of Medicine's (NAM) Leadership Consortium for a Value and Science-Driven Health System (2013) states: Care that is significant is frequently not conveyed. Care that is conveyed is frequently not significant. In huge part, the bungle results from the inability to refresh and apply the accessible proof.

The quickly expanding development in analytic and treatment alternatives quickened even more by progresses in genomics and proteomics and the prospering measure of accessible clinical information presents a steady and continuous hole among training and potential. This hole will grow except if a methodical exertion is attempted to create and apply apparatuses that can quicken the catch, evaluation, 
approval, interpretation, and continuous conveyance of best accessible, suitably custom fitted proof for purpose of care choices by wellbeing laborers. Dynamic rules, prompts, and helps, clinical choice help instrument (CDS) that convey the best accessible data consistently and successfully to the point of clinical choices), are important for improved and effective consideration. Despite the fact that it is actually possible to convey opportune, approved proof in a valuable style to clinical specialists, the real usage of such help has commonly been the exemption as opposed to the standard. Usage of CDS apparatuses experienced by clinical specialists to date, have regularly been costly, troublesome, conflicting, discredited, and not introduced in convenient or liquid focuses in the choice cycle. In the most recent decade, electronic wellbeing record (EHR) appropriation rates have taken off by the clinical specialists. Starting at 2015, 87 percent of office-based doctors had received any EHR, 78 percent had embraced an affirmed EHR, and 54 percent had received a Basic EHR, (Jamoom and Yang 2016), preparing for expanded utilization of CDS devices that influence EHR information to give choice help to clinical specialists and patients. Compact discs abilities working together with EHRs hold incredible potential to help the country's medical services frameworks give admittance to the best current proof in usable structure and at vital focuses inside consideration and dynamic cycles to help clinical specialist, patients, and other consideration colleagues improve medical care results and lower the general expense of care. As portrayed by the Office of the National Coordinator for wellbeing Information Technology (ONC), CDS gives clinical specialists, staff, patients, and others with information and individual explicit data, cleverly sifted or introduced at suitable occasions, to upgrade wellbeing and medical care. Discs envelops an assortment of apparatuses to improve dynamic in the clinical work process. These instruments incorporate modernized cautions and suggestions to mind suppliers and patients; clinical rules; condition-explicit request sets; centered patient information reports and rundowns; documentation layouts; demonstrative help, and logically pertinent reference data, among different apparatuses. Cds is a complex wellbeing IT usefulness that accomplishes more than give cautions, notices, or unequivocal consideration proposals.

Albums requires calculable biomedical data, individual explicit information, and a thinking or deduction system that joins information and information to create and introduce supportive data to clinical specialists as care is being conveyed. Kawamoto and Lobach (2005) believed that data should be sifted, coordinated, and introduced such that bolsters the current work process, permitting the client to settle on an educated choice rapidly and to make a move on that choice. Various sorts of CDS might be ideal for various cycles of care in various settings, and viable CDS should be pertinent to the individuals who can follow up on the data such that upholds culmination of the correct activity. Cds isn't planned to supplant clinical specialist judgment, but instead to give data to help care colleagues in dealing with the complex and extending volume of biomedical and individual explicit information expected to make opportune, educated, and greater choices dependent on current clinical science. Discs apparatuses can be coordinated toward decrease of mistakes and unfriendly occasions, advancement of best practices for quality and security, cost profile improvement, fast reaction to general wellbeing crises, and all the more, for example, supporting shared dynamic or fitting plans of treatment to tolerant inclinations. A developing collection of writing shows the positive effect CDS can have on consideration measures, clinical results, and monetary results. The Agency for Healthcare Research and Quality (AHRQ) dispatched a writing survey in 2012 that discovered demonstrating that CDS had positive effect on cycle measures, for example, how dependably wellbeing laborers requested vital and proof based preventive and therapy administrations, and on expanding client information applicable to an ailment (Lobach, Sanders, Bright, Wong and Erin 2012). Studies have indicated that professional CDS can lessen unfriendly occasions from drug-drug collaborations (Zheng, Abraham, Novak, Reynolds and Gettinger 2016) and medicine mistakes (Fritz, Childs, Wainner and Flynn 2012); decline superfluous research facility testing (Felcher, Gold, Mosen and Stoneburner 2017); diminish cardiovascular danger in patients with type 2 diabetes (Cleveringa, Gorter, Donk and Rutten 2007); improve specialist execution (Garg, Adhikari, McDonald, Rosas-Arellano, 
Devereaux, Beyere, Sam and Haynes 2005); increment cardiovascular infection hazard evaluation in routine essential consideration practice (Wells and Bullen 2008); improve general wellbeing results related with episodes of foodborne ailment ( $\mathrm{Wu}, \mathrm{Li}$ and $\mathrm{Fu} 2011)$; and produce cost reserve funds related with clinic based drug store mediations (Calloway, Akilo and Bierman 2013). Taken together, the accessible proof shows that while there is huge opportunity to get better, CDS in the correct setting executed appropriately with the correct sort of the board can decrease blunders, improve the nature of care, lessen cost, and facilitate the intellectual weight on medical services suppliers. Accordingly, accomplishing far and wide appropriation of CDS by the country's wellbeing frameworks and suppliers will be basic to guaranteeing that the significant and continuous interests in biomedical science and development are made an interpretation of as advantages to American citizens regarding improved wellbeing and medical services in an extraordinarily quickened time span.

In reality, in a 10-year vision articulation for wellbeing IT-empowered quality improvement, Office of the National Coordinator for Health data Technology (ONC) called for propelling wellbeing IT abilities revolved around $\mathrm{CDS}$ and clinical quality estimation to empower vigorous and consistent quality improvement (ONC, 2014). These wellbeing IT capacities will give all individuals from the clinical consideration group continuous admittance to the best accessible proof in a manner that is lined up with and doesn't add weights to their all around hefty remaining task at hand, however that rather exploits the huge advances in registering power and computational investigation to assist them with overseeing, acclimatize, and apply the best accessible proof to help settling on better decisions that lead to better results for all patients. In spite of its latent capacity, CDS execution and realization stay early because of the numerous hindrances to understanding the full advantages of CDS-encouraged worth improvement. A key obstruction is the current requirement for most medical services associations to freely create, convey, and oversee CDS content, prompting significant expenses and repetitive work across the framework. To address these difficulties and understand the maximum capacity of CDS inside genuine conditions requires the recognizable proof of key needs for activity zeroed in on accomplishing the capability of these instruments to improve the quality, security, and productivity of medical services.

\subsection{Theoretical Framework}

The function of theory in research is predicated on the felt needs establishing a cause and effect relationship between variables with the purpose of explaining and predicting phenomenon (Hersh, 2010). In view of this it has become imperative to consider some theories that are of practical application to this research. From available literature however, it is apparent that no single theory can adequately capture the relationship between information availability and utilisation and job performance. Therefore, the study was anchored on two theories found relevant to the variables of the study. These are: Organisational Information Theory (OIT) and Organisational Information Processing Theory (OIPT)

\subsubsection{Organizational information theory $($ OIT)}

This theory was developed by (Karl Weick, 1979) and was further studied and described by (Ali, Talpur, Alamgir and Javed, 2015) as fundamental understanding into the handling and trade of data inside associations and among its individuals. Not at all like the previous structure-focused hypothesis, OIT centers around the way toward getting sorted out in powerful, data rich conditions. Given that, it substance that the principle movement of associations is the way toward sorting out dubious data. Hierarchical individuals are instrumental to lessen dubiousness and accomplish sense making through some system's 
order, choice and maintenance of data

\subsubsection{The relevance of the theory to this study (OIT)}

The theory concentrates on how information is obtained, collected, managed and used to influence the decision in an organization. Therefore, the primary focus of the theory is on the exchange of information among the member in an organization, and how members take steps to understand this information for clinical decision making. A key component of Weick's theory is the information afforded by the organization's environment, including the culture within the organizational environment, urgency and importance of, which can impact the behaviours and interpretation of behaviours of those clinical specialists. Thus, the sourcing for information by clinical specialists is impacted by each person's personal schema, knowledge, experience as well as the backdrop of the organization's objectives. According to him, the clinical specialists must sift through the available information to filter out the valuable from the extraneous. Additionally, the clinical specialists must both interpret the information and coordinate that information to "make it meaningful for the situation at hand." In order to construct meaning from these messages in their environment, the organisation must reduce equivocality and commit to an interpretation of the message. Using established rules such a duration, personnel, success and effort the organization.

Summarily, OIT focuses on the communication of information that is vital in taking a life or death clinical decision. However, the task of information processing is not completed simply by attaining information; the harder part is deciphering and interpreting the information gained to proffer solution to the health challenges of a patient.

The implication of the theory for this study is that because of the wide range of clinical information needs of health workers the sources required must be available, accessible and dependable. Likewise, the preferred format and the preferred method of accessing the information should be established before the clinical specialists can use it, and this is only when effective clinical decision can be enhanced.

\subsubsection{The organizational information processing theory (OIPT)}

The authoritative data handling hypothesis (OIPT) was created by Galbraith (1973). Bergman, Platonov, Dukeov and Luka (2016) later distinguished three significant ideas information getting ready necessities, information taking care of capacity, and the fit between the two to get ideal execution. Extraordinary theory variation portrays weakness, especially task weakness as the determinant of an associations' structure. Association need quality data to adapt to ecological vulnerability and improve their dynamic. Normally, associations have two systems to adapt to vulnerability and expanded data needs (1), create cushions to decrease the impact of vulnerability and (2), execute primary instruments and data preparing ability to upgrade the data stream and, in this manner, lessen vulnerability

\subsubsection{The relevance of the theory to this study (OIPT)}

The Organisational Information Processing Theory propended by Galbraith (1973), As indicated by him clinical specialists need quality data to adapt to the vulnerability that encompass their work and improve their dynamic. Ecological vulnerability he recommended comes from the multifaceted nature of the climate and dynamism, or the recurrence of changes to different ecological factors. Regularly, he believed that wellbeing laborers have two techniques to adapt to vulnerability and expanded data needs: (I) create cushions to diminish the impact of vulnerability, and (ii) execute primary components and data preparing ability to improve the data stream and accordingly lessen vulnerability. An exemplary illustration of the 
primary system is building stock supports to lessen the impact of vulnerability sought after or supply; another model is adding additional security cushions in item configuration because of vulnerability in item working conditions. An example of the second strategy is the redesign of business processes in organizations and implementation of integrated Information system that improves information flow and reduces uncertainty within organizational subunits. A similar strategy is creating better information flow between clinical specialists (information sharing) to address the uncertainties in the supply chain.

The implication for this study is that the quality of health information packaged is required to reduce problems of health and safety and the procedure put in place to ensure its availability to the health information professional will impact on effective clinical decision making. It is only when there is adequate health information that it could be utilised by clinical specialists and that is when health and safety and improved clinical decision can be guaranteed.

\subsection{Conceptual framework}

A concept is a word or phrase that symbolises several interrelated ideas, while a model has been described as an intellectual construct in artifact that provides an abstract, highly formalized, often visual yet simplified representation of a phenomenon and its interaction (Hollander and Moreno 2012), Typically a model can include those variables that are sufficient to represent the phenomena in question (Graham, 2007) The conceptual framework of this study is based on the assumption that health information access and use will impact on effective and efficient clinical decision making of clinical specialists in OAUTH. In this regard, the conceptual diagram of the study is presented in Figure 1. 


\section{Conceptual Model}

INDEPENDENT VARIABLES

DEPENDENT VARIABLE

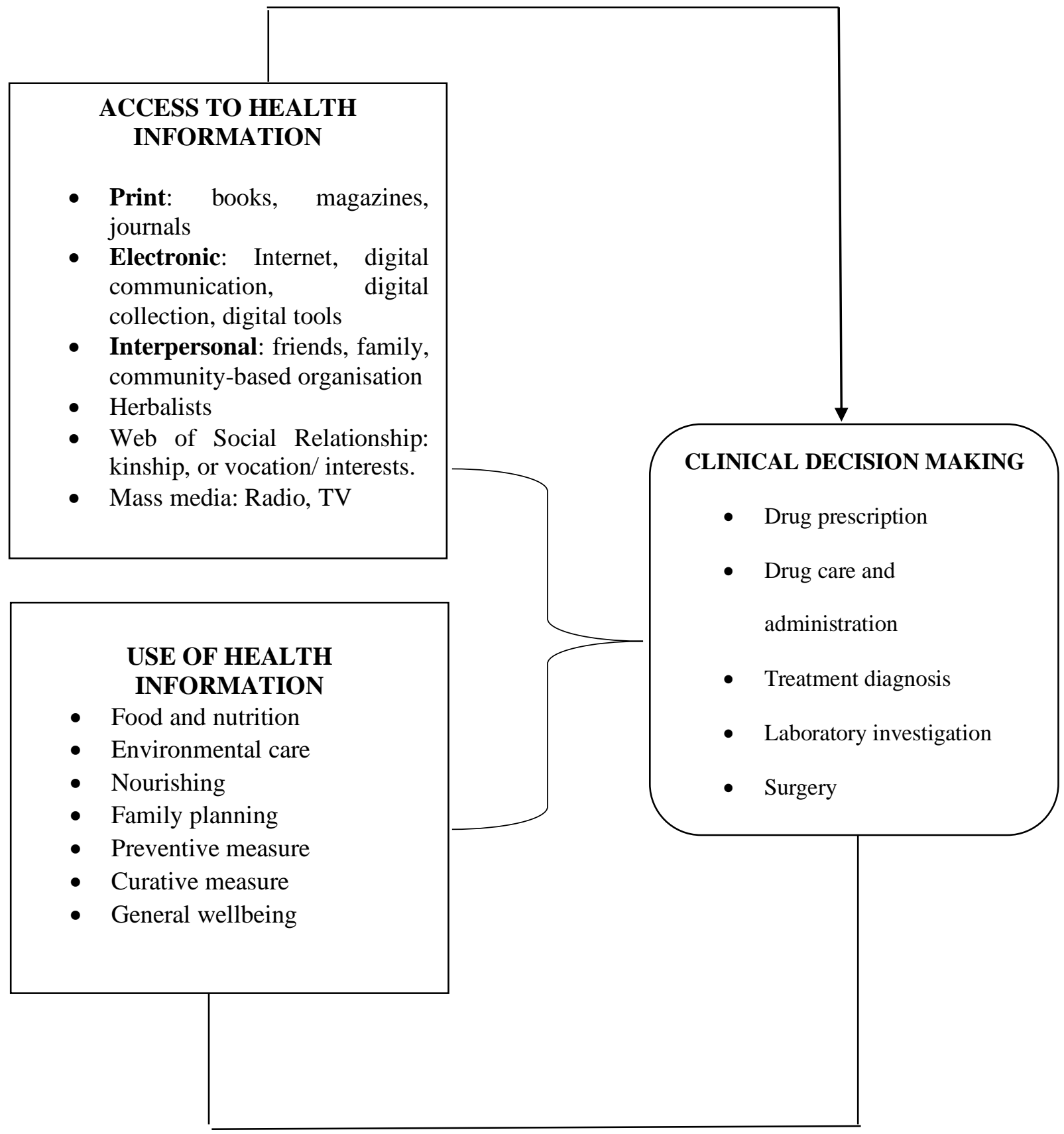


Source: Designed by the researcher, 2019.

Figure 1: Conceptual model showing the health information access and use for clinical dynamics among clinical specialists of Obafemi Awolowo University Teaching Hospital

Figure 1 show the conceptual model of the study. It is assumed that accessibility of health information from mass media: radio, TV, newspapers; web of social relationship: friendship, kinship, or vocation/ interests; Formal educational programme; cognitive skills; print media: newspaper, general magazine when utilised could enhance clinical decision making of health workers in their day-to-day care for human health challenges. Utilisation is the most important attributes of any source of information and if utilised as in the model above should also serve as a critical factor that can enhance efficient clinical decision making and health care services.

Health information access and use is vital to efficient clinical decision making, but before health information can be made use of, it has to be accessible and useful. Any decision maker's most especially medical doctor should know how to source for health information that will be useful, and dependable for clinical dynamics. This means that the source of health information must be trusted. In the case of health information provision to clinical specialists, the only body that could make such information available to medical doctor are health information professionals

\subsection{Appraisal of the literature reviewed}

This review has shown that health information is of utmost importance to the society at large and the clinical specialists in particular. It has also shown that clinical specialists need health information to improve their knowledge and in making decisions that could improve their health and safety emanated from efficient clinical decision making. Clinical specialists can therefore try to meet their clinical information needs by utilizing the health information sources which are accessible to them and which they feel comfortable to use. Some studies on health information availability and utilisation have been carried out in many occupations like construction, engineering, farming, manufacturing but it appears there is lack of emphasis on the manner in which the concept is related to the circumstances of health workers in respect of clinical decision making. Health informational factors such as accessibility and utilisation have not been considered as crucial factors that can enhance or affect the quality of clinical dynamics of clinical specialists in OAUTH, in Nigeria. This is the main thrust of this study.

\subsection{Methodology}

This section depicted the approach utilized for the examination. The part introduced the examination plan, populace of the investigation, testing strategy and test size, inspecting technique, legitimacy and dependability of the instrument, methodology for information assortment and strategy for information examination

\subsection{Research design}

The study used descriptive research design of correlational type. Expressive exploration configuration is a logical technique which includes noticing and depicting the conduct of a subject without directing it in 
any capacity. It involves the design and administration of an instrument to the respondents.

\subsection{Population of the study}

The number of inhabitants in the examination comprised of the clinical experts from Obafemi Awolowo Teaching Hospital (OAUTH), Ile-Ife, Osun State, Nigeria. The complete populace was 800 and 22 (822) clinical experts of different expert status in OAUTH.

Table 1 Shows the professional status of clinical specialists and their corresponding numbers as population of the study:

Table 1: Population of the study

\begin{tabular}{lll} 
S/N & Clinical specialists & Population \\
\hline 1 & Consultants & 174 \\
2 & House Officers & 105 \\
3 & Residents & 503 \\
4 & Supernumerary & 40 \\
\hline & TOTAL & 822
\end{tabular}

\subsection{Sampling technique and sample size}

The sampling technique that was adopted for the study was a multi-stage sampling technique. At first stage, purposive sampling technique was used to select the teaching hospitals to be examined. Obafemi Awolowo University Teaching hospital was purposively selected because of its age-long existence and federal status. OAUTH was one of the foremost university teaching hospitals established in Southwestern Nigeria. The classes of clinical experts that were chosen for the examination were Consultants, Senior Registrars, Registrars, Medical Officers and House Officers.

Table 2 depicts the sample size for the study:

Consultants $=174 / 822 \times 265=56.09$

House officers $=105 / 822 \times 265=34.08$

Residents $=503 / 822 \times 265=162.01$

Supernumerary $=40 / 822 \times 265=12.89$

Table 2: Sample size of the study

\begin{tabular}{llcl} 
S/N & Clinical specialists & Population & Sample Size \\
\hline 1 & Consultants & 174 & 56 \\
2 & House Officers & 105 & 34 \\
3 & Residents & 503 & 162 \\
4 & Supernumerary & 40 & 13 \\
\hline & Total & $\mathbf{8 2 2}$ & $\mathbf{2 6 5}$
\end{tabular}

\subsection{Instrument for data collection}

Both quantitative and subjective information were accumulated for the examination utilizing a bunch of poll and supplemented with a center gathering conversation (FGD). The questionnaire was tagged: Access and Use of Health Information Tools for Clinical Decision Making among the Clinical specialists in 
Obafemi Awolowo University Teaching Hospital (AUHIRCDMMDOAUTH). The questionnaire comprised of four (4) main sections namely sections A-D. Three (3) out of the four (4) sections was based on a four-points Likert scale (4=High, 1= Low).

Section A addressed the medical doctor's socio-demographic characteristics. It consisted of 7 items including gender, age, marital status, Professional Status, specialization, the name of Institution and position held by the respondents. Section B addressed Access to Health Information Tools and comprised 12 items. Section C dwelled on Use of Health Information Tools comprised 12 items. This section also asked questions on sources of health information for clinical decision making among clinical specialists. Section D: This section elicited questions on clinical decision making among the clinical specialists. 3.5 Validity and reliability of the instrument

To ensure the face validity of the instrument for the study, the questionnaire was given to the supervisor and lecturers in the Department of Communication and General Studies (CGNS) of Federal University of Agriculture, Abeokuta, and other experts in the field of Library and Information Science. Corrections was made based on their criticisms, observations, comments and suggestions. Reliability test was carried out at Federal Medical Center, Abeokuta. The research instrument was administered using twenty clinical specialists. The respondents from this institution did not form part of this study. Cronbach Alpha coefficient was used to test the reliability of the instrument. Table 3 presents the results of the reliability study.

Table 3: Reliability of the instrument

\begin{tabular}{|c|c|c|c|}
\hline $\mathbf{S} / \mathbf{N}$ & Research question & Cronbach's alpha & No of items \\
\hline 1 & $\begin{array}{l}\text { Which of these health information tools are accessible to you } \\
\text { for clinical decision making }\end{array}$ & .931 & 24 \\
\hline 2 & How accessible are these health information tools to you & .947 & 22 \\
\hline 3 & $\begin{array}{l}\text { How often do you access these health information tools for } \\
\text { clinical decision making }\end{array}$ & .887 & 22 \\
\hline 4 & $\begin{array}{l}\text { To what extent do you use the health information tools for } \\
\text { clinical decision making }\end{array}$ & .956 & 22 \\
\hline 5 & $\begin{array}{l}\text { How often do you use these health information tools for } \\
\text { clinical decision making }\end{array}$ & .944 & 22 \\
\hline 6 & $\begin{array}{l}\text { To what extent do you use your core skills for clinical } \\
\text { decision making }\end{array}$ & .987 & 13 \\
\hline 7 & $\begin{array}{l}\text { What are the problems hindering effective health information } \\
\text { utilisation among clinical specialists }\end{array}$ & .967 & 13 \\
\hline & TOTAL & 6.619 & 0.9541 \\
\hline
\end{tabular}

\subsection{Data collection procedure}

A letter of Introduction from the Head of Department of Communication and General Studies, Federal University of Agriculture, Abeokuta was submitted at the Obafemi Awolowo University Teaching Hospital, Ile-Ife. This was with a view to getting ethical clearance from the Ethics and Research Committee of the teaching hospital.

A total of 265 copies of the questionnaire was administered on the respondents with the help of trained research assistants. Data was gathered over a period of five weeks. The researcher and research assistants administered the questionnaire on the respondents at their various departments. The copies of the questionnaire were completed by the clinical specialists on "drop and collect later basis". Center gathering conversation (FGD) was likewise held among the two gatherings of clinical experts with four (4) individuals in each gathering adding up to eight members. Structured questions on the subject of study were raised by the researcher to guide the discussion and moderate the session. The discussions were recorded in 
a midget and was transcribed later into a readable form

\subsection{Method of data analysis}

The descriptive method of data analysis, including frequency counts, simple percentage, mean, standard deviation and inferential statistics, simple correlations and Multiple Regression was used to analyze the quantitative data in this study. Two main statistical techniques including Pearson's Product Moment Correlation (PPMC) was used to analyze hypothesis 1-3 and Multiple Linear Regression was employed to analyze hypotheses 4 and 5. The International Business Machine Statistical Package for Social Sciences (IBMSPSS 20) was used to analyze the quantitative data. Qualitative data was also analyzed in this study. The discussions from FGD were recorded and later transcribed to reinforce the findings of the study as the case maybe. 


\subsection{Results and discussion}

This chapter presents the results and discussions of finding based on the objectives raised, research questions answered, hypotheses tested, and data extracted from the focus group discussion conducted in the study.

\subsection{Questionnaire distribution and return rate}

Two hundred and fifty-nine (259) copies of the questionnaire were retrieved out of two hundred and sixty-five (265) administered. This represents $98 \%$ response rate.

Focus group discussion was also used as a research instrument in this study. A center gathering conversation includes gathering individuals from comparative foundations or encounters together to examine a particular subject of interest, it is a type of subjective examination where inquiries are posed about their discernment's perspectives, convictions, assessment or thoughts. The substance of center gathering conversation was to utilize the outcome that exude from the center gathering conversation to praise or enhance the outcome that were discovered dependent on the examination of the poll that were circulated and recovered as the exploration instrument. Center gathering conversations were led among two gatherings comprising of the clinical specialists from OAUTH. Structured questions were used to guide the discussions among the members of the two groups. The results of the focus group discussion were used to either corroborate, compliment, supplement or to contrast with the results from the questionnaire as the case may be.

Table 4 Questionnaire administration and return rate S/N Selected hospital

No of
questionnaire

administered
No of $\quad \%$ of questionnaire returned

questionnaire and analyzed

returned and

analyzed

\begin{tabular}{lllll}
\hline 1 & Obafemi Awolowo & 265 & 259 & $97.7 \%$ \\
& University Teaching & & \\
Hospital Ile-Ife & & &
\end{tabular}

\section{Table 4 b Focus group discussion}

\begin{tabular}{llll}
$\mathrm{S} / \mathrm{N}$ & Group number & Number of participants & Field of discipline \\
1 & 1 & 4 & Clinical specialists \\
2 & 2 & 4 & Clinical specialists \\
\hline
\end{tabular}


Table 5 showed the demographic information of clinical specialists of Obafemi Awolowo University Teaching Hospital, Ile-Ife. $155(59.8 \%)$ of the respondents were male and $104(40.2 \%)$ were female, 58 (22.4\%) of the respondents were Consultants, 32 (12.4\%) were senior registrars, $76(29.3 \%)$ were Registrars, $71(27.4 \%)$ were Medical officers, $14(5.4 \%)$ were House officers $8(3.1 \%)$ were Supernumerary officers. 76 $(29.3 \%)$ of the respondents were between $20-29$ years, $86(33.2 \%)$ were between $30-39$ years, $62(23.9 \%)$ were between 40-49 years, 30 (11.6\%) were between 50-59 years, and 5 (1.9\%) were between 60-69 years of age. $95(36.7 \%)$ of the respondents were single, $142(54.8 \%)$ were married, and $22(8.5 \%)$ were divorced. 29 $(11.2 \%)$ of the respondents specialized in family medicine, $5(1.9 \%)$ specialized in rheumatology, $9(3.5 \%)$ specialized in mental health, $64(24.7 \%)$ specialized in G.P, $12(4.6 \%)$ were physicians, $4(1.5 \%)$ specialized in genealogy, $22(8.5 \%)$ specialized in medicine and surgery, $13(5.0 \%)$ specialized in central practice, 13 $(5.0 \%)$ specialized in Medicine, $2(0.8 \%)$ specialized in psychiatry, $1(0.4 \%)$ specialized in community health and $5(1.9 \%)$ specialized in neurosurgery. 77 (29.7\%) had MWACP certificate, 51 (19.7\%) had FWACP certificate, $95(36.7 \%)$ had MBCHB certificate and $36(13.9 \%)$ had MBBS certificate.

4.2 Demographic information of clinical specialists in Obafemi Awolowo University Teaching Hospital, Ile-Ife. Table 4.2:

Gender Frequency distribution of the respondents by gender

Male Frequency Percentage

Female $155 \quad 59.8$

Total 104 40.2

Frequency distribution of the respondents by age

\begin{tabular}{lll} 
Age & Frequency & Percentage \\
\hline $20-29$ years & 76 & 29.3 \\
$30-39$ years & 86 & 33.2 \\
$40-49$ years & 62 & 23.9 \\
$50-59$ years & 30 & 11.6 \\
60-69 years & 5 & 1.9 \\
Total & $\mathbf{2 5 9}$ & 100.0 \\
\hline \multicolumn{2}{c}{ Frequency distribution of the respondents by marital status } \\
Marital status & Frequency & Percentage \\
\hline Single & 95 & 36.7 \\
Married & 142 & 54.8 \\
Divorced & 22 & 8.5 \\
Total & $\mathbf{2 5 9}$ & $\mathbf{1 0 0 . 0}$ \\
\hline
\end{tabular}

\begin{tabular}{|c|c|c|}
\hline Total & 259 & \\
\hline Frequency & of the respo & \\
\hline Field specialization & Frequency & Percentage \\
\hline Family medicine & 29 & 11.2 \\
\hline Rheumatology & 5 & 1.9 \\
\hline Mental health & 9 & 3.5 \\
\hline G.P & 64 & 24.7 \\
\hline Physician & 12 & 4.6 \\
\hline
\end{tabular}




\begin{tabular}{lll}
\hline Genealogy & 4 & 1.5 \\
Medicine surgery & 22 & 8.5 \\
Central practice & 93 & 35.9 \\
Medicine & 13 & 5.0 \\
Psychiatry & 2 & 0.8 \\
Community health & 1 & 0.4 \\
Neurosurgery & 5 & 1.9 \\
Total & $\mathbf{2 5 9}$ & $\mathbf{1 0 0 . 0}$ \\
\hline \multicolumn{3}{c}{ Frequency distribution of the respondents by level of qualification } \\
Highest qualification & Frequency & Percentage \\
\hline MWACP & 77 & 29.7 \\
FWACP & 51 & 19.7 \\
MBCHB & 95 & 36.7 \\
MBBS & 36 & 13.9 \\
Total & $\mathbf{2 5 9}$ & $\mathbf{1 0 0 . 0}$ \\
\hline & Frequency distribution of the respondents by professional status & \\
Professional status & Frequency & Percentage \\
\hline Consultant & 58 & 22.4 \\
Senior Registrar & 32 & 12.4 \\
Registrar & 76 & 29.3 \\
Medical Officer & 71 & 27.4 \\
House officer & 14 & 5.4 \\
Supernumerary & 8 & 3.1 \\
Total & $\mathbf{2 5 9}$ & $\mathbf{1 0 0 . 0}$ \\
\end{tabular}

Research objective one: The various health information tools accessible for clinical decision making among clinical specialists in OAUTH

Table 6 demonstrated the different wellbeing data assets available for clinical dynamic among clinical experts in OAUTH. It shows that CT Scan $(\bar{x}=3.49)$ positioned most noteworthy by the mean score rating and was continued in progression by ECG machine (3.40), Incubator $(\bar{x}=3.15)$ and Orthoscopic $(\bar{x}=$ 3.15). Magnifying instrument ( $\bar{x}=2.92)$ and Teleconferencing ( $\bar{x}=2.91$ ) were the least things showed by the respondents. The derivation drawn from the above outcome is that CT Scan, ECG machine, hatchery, Orthoscopic, Radiograph, GSM telephones, I cushion, I unit, magnifying instrument and PC framework were the significant wellbeing data assets open for clinical dynamic among clinical experts in OAUTH. The purpose behind this is on the grounds that these were the things that positioned over the weighted mean of $\bar{x}=3.05$ set as the benchmark. This examination likewise discovered from the center gathering conversation that was held among the gathering of clinical experts in OAUTH that the significant essential wellbeing data assets that were accessible in the medical clinic to help the clinical experts in their dynamic cycle incorporate hardware, for example, CT check, ECG machine, Radiograph, Magnetic reverberation imaging (MRI) and furthermore Sphygmomanometer. The discoveries from this examination concurred with Schiavo's (2007) study where he declared that wellbeing correspondence is a way to deal with pass on data with the objective of improving wellbeing results by empowering conduct alteration and social change through the continuum of information, convictions and perspectives, and conduct. This finding also supports Hay, Coup, Ford, DiBonaventura (2009) finding that health communication strategies utilizing mass media such as TV, print, and Internet have been associated with health beliefs and behaviours. The most exceptionally heaps of data were from other wellbeing laborers and companions dispersing proof. Rather than wellbeing laborers in numerous different investigations who would in general advantage proof 
got from work-ר-based exercises, for example, clinical experience or from communication with senior nursing or clinical partners (Jansson and Forsberg, 2016).

Table 6 Various health information tools accessible for clinical decision making among clinical specialists in OAUTH

\begin{tabular}{|c|c|c|c|c|c|c|c|}
\hline $\mathbf{s} / \mathbf{n}$ & $\begin{array}{l}\text { Access to health } \\
\text { information tools }\end{array}$ & HA & MA & $\mathbf{R A}$ & NA & $\overline{\mathbf{x}}$ & S.D \\
\hline \multirow[t]{2}{*}{1} & CT Scan & 144 & 97 & 18 & - & 3.49 & 0.62 \\
\hline & & $55.6 \%$ & $37.5 \%$ & $6.9 \%$ & & & \\
\hline \multirow[t]{2}{*}{2} & ECG machine & 133 & 102 & 19 & 5 & 3.40 & 0.71 \\
\hline & & $51.4 \%$ & $39.4 \%$ & $7.3 \%$ & $1.9 \%$ & & \\
\hline \multirow[t]{2}{*}{3} & Incubator & 97 & 116 & 31 & 15 & 3.15 & 0.88 \\
\hline & & $37.5 \%$ & $44.8 \%$ & $12.0 \%$ & $5.8 \%$ & & \\
\hline \multirow[t]{2}{*}{4} & Orthoscopic & 87 & 131 & 33 & 8 & 3.15 & 0.75 \\
\hline & & $33.6 \%$ & $50.6 \%$ & $12.7 \%$ & $3.1 \%$ & & \\
\hline \multirow[t]{2}{*}{5} & Radiograph & 123 & 71 & 41 & 24 & 3.13 & 1.00 \\
\hline & & $47.5 \%$ & $27.4 \%$ & $15.8 \%$ & $9.3 \%$ & & \\
\hline \multirow[t]{2}{*}{6} & GSM phones, I pad, I pod & 110 & 93 & 32 & 24 & 3.12 & 0.95 \\
\hline & & $42.5 \%$ & $35.9 \%$ & $12.4 \%$ & $9.3 \%$ & & \\
\hline \multirow[t]{2}{*}{7} & Microscope & 103 & 99 & 33 & 24 & 3.08 & 0.94 \\
\hline & & $39.8 \%$ & $38.2 \%$ & $12.7 \%$ & $9.3 \%$ & & \\
\hline \multirow[t]{2}{*}{8} & Computer system & 98 & 103 & 37 & 21 & 3.07 & 0.92 \\
\hline & & $37.8 \%$ & $39.8 \%$ & $14.3 \%$ & $8.1 \%$ & & \\
\hline \multirow[t]{2}{*}{9} & Telemedicine & 98 & 106 & 22 & 33 & 3.04 & 0.99 \\
\hline & & $37.8 \%$ & $40.9 \%$ & $8.5 \%$ & $12.7 \%$ & & \\
\hline \multirow[t]{2}{*}{10} & Electronic BP Gauge & 96 & 104 & 30 & 29 & 3.03 & 0.97 \\
\hline & & $37.1 \%$ & $40.2 \%$ & $11.6 \%$ & $11.2 \%$ & & \\
\hline \multirow[t]{2}{*}{11} & Autoclave & 79 & 116 & 51 & 13 & 3.01 & 0.84 \\
\hline & & $30.5 \%$ & $44.8 \%$ & $19.7 \%$ & $5.0 \%$ & & \\
\hline \multirow[t]{2}{*}{12} & Internet & 91 & 106 & 32 & 30 & 3.00 & 0.97 \\
\hline & & $35.1 \%$ & $40.9 \%$ & $12.4 \%$ & $11.6 \%$ & & \\
\hline \multirow[t]{2}{*}{13} & CD ROM & 92 & 104 & 35 & 28 & 3.00 & 0.96 \\
\hline & & $35.5 \%$ & $40.2 \%$ & $13.5 \%$ & $10.8 \%$ & & \\
\hline \multirow[t]{2}{*}{14} & DVD & 89 & 104 & 42 & 24 & 3.00 & 0.94 \\
\hline & & $34.4 \%$ & $40.2 \%$ & $16.2 \%$ & $9.3 \%$ & & \\
\hline \multirow[t]{2}{*}{15} & Glucometer & 86 & 110 & 39 & 24 & 3.00 & 0.93 \\
\hline & & $33.2 \%$ & $42.5 \%$ & $15.1 \%$ & $9.3 \%$ & & \\
\hline \multirow[t]{2}{*}{16} & Sphygmomanometer & 74 & 125 & 44 & 16 & 2.99 & 0.84 \\
\hline & & $28.6 \%$ & $48.3 \%$ & $17.0 \%$ & $6.2 \%$ & & \\
\hline \multirow[t]{2}{*}{17} & Videoconferencing & 86 & 106 & 42 & 25 & 2.98 & 0.94 \\
\hline & & $33.2 \%$ & $40.9 \%$ & $16.2 \%$ & $9.7 \%$ & & \\
\hline \multirow[t]{2}{*}{18} & Hemoglobin & & 101 & & 24 & 2.96 & 0.94 \\
\hline & electrophoresis & $33.2 \%$ & $39.0 \%$ & $18.5 \%$ & $9.3 \%$ & & \\
\hline
\end{tabular}




\begin{tabular}{llllllll}
19 & Video & 85 & 103 & 45 & 26 & 2.95 & 0.95 \\
& & $32.8 \%$ & $39.8 \%$ & $17.4 \%$ & $10.0 \%$ & & \\
20 & VCD & 81 & 106 & 48 & 24 & 2.94 & 0.93 \\
& & $31.3 \%$ & $40.9 \%$ & $18.5 \%$ & $9.3 \%$ & & \\
21 & Projectors & 81 & 105 & 44 & 29 & 2.92 & 0.96 \\
& & $31.3 \%$ & $40.5 \%$ & $17.0 \%$ & $11.2 \%$ & & \\
22 & Teleconferencing & 77 & 109 & 45 & 28 & 2.91 & 0.95 \\
& & $29.7 \%$ & $42.1 \%$ & $17.4 \%$ & $10.8 \%$ & & \\
\hline
\end{tabular}

Weighted mean $=\mathbf{3 . 0 5}$

KEY: HA=Highly Accessible, MA=Moderately Accessible, RA= Rarely Accessible, NH=Not Accessible

\section{Research objective two: The level of accessibility of health information tools for clinical decision making among clinical specialists in OAUTH}

Table 7 showed the accessibility of health information tools for clinical decision making among clinical specialists in OAUTH. It shows that ECG machine $(\bar{x}=3.44)$ ranked highest by the mean score rating and was followed in succession by CT Scan $(\bar{x}=3.22)$, GSM phone, ipad, ipod $(\bar{x}=3.08)$. Radiograph $(\bar{x}=2.76)$ and Electronic BP Gauge ( $\bar{x}=2.71)$ were the least items indicated by the respondents

The inference drawn from this, using the weighted mean of 3.00, was that ECG machine, CT scan, GSM phone ipad, ipod, Autoclave, Teleconferencing, Internet, hemoglobin electrophoresis, Sphygmomanometer, VCD and Microscope were the highly accessible.

This examination additionally discovered from the center gathering conversation that was held among the gathering of clinical specialists in OAUTH fair and square of openness of wellbeing data assets for clinical dynamic, that wellbeing data assets, for example, CT check, radiograph machine, and autoclave were exceptionally available. Another conspicuous truth appeared in the discoveries of the investigation was that the degree of availability to wellbeing data assets for clinical dynamic among clinical specialists in OAUTH were declared to be exceptionally high. This finding supports the works of earlier researchers like Moon, Hossain and Shin (2012) who in their study admitted that access to accurate medical information, in various health care facilities, was very necessary for clinical specialists to take effective medical decision. Hence, it could be deduced that the accessibility level is high. This study also corroborated Attama and Ezema (2005) who found that access and use of information are necessary to clinical specialists for problem solving and decision making. This is pertinent because information tools are used by the clinical specialists to complement their knowledge and clinical experience and to keep themselves up to date. Electronic clinical information tools continue to expand in accessibility and are an important reference for the clinical specialists. Further, designers of electronic data assets are coordinating these productive and viable assets into clinical data frameworks (CISs) to help the data needs of the clinical specialists. Access to adequate medical information is imperative for successful healthcare delivery, particularly, for clinical specialists all over the world. 
Table 7 Level of accessibility to health information tools for clinical decision making among clinical specialists in OAUTH

\begin{tabular}{|c|c|c|c|c|c|c|c|}
\hline $\mathbf{s} / \mathbf{n}$ & Health Information tools & HA & MA & $\mathbf{R A}$ & NA & $\bar{x}$ & S.D \\
\hline \multirow[t]{2}{*}{1} & ECG machine & 140 & 99 & 15 & 5 & 3.44 & 0.69 \\
\hline & & $54.1 \%$ & $38.2 \%$ & $5.8 \%$ & $1.9 \%$ & & \\
\hline \multirow[t]{2}{*}{2} & CT Scan & 78 & 167 & 8 & 6 & 3.22 & 0.61 \\
\hline & & $30.1 \%$ & $64.5 \%$ & $3.1 \%$ & $2.3 \%$ & & \\
\hline \multirow[t]{2}{*}{3} & GSM phones,I pad, I pod & 99 & 108 & 25 & 27 & 3.08 & 0.95 \\
\hline & & $38.2 \%$ & $41.7 \%$ & $9.7 \%$ & $10.4 \%$ & & \\
\hline \multirow[t]{2}{*}{4} & Autoclave & 92 & 113 & 33 & 21 & 3.07 & 0.90 \\
\hline & & $35.5 \%$ & $43.6 \%$ & $12.7 \%$ & $8.1 \%$ & & \\
\hline \multirow[t]{2}{*}{5} & Teleconferencing & 93 & 103 & 45 & 18 & 3.05 & 0.90 \\
\hline & & $35.9 \%$ & $39.8 \%$ & $17.4 \%$ & $6.9 \%$ & & \\
\hline \multirow[t]{2}{*}{6} & Internet & 90 & 111 & 35 & 23 & 3.03 & 0.92 \\
\hline & & $34.7 \%$ & $42.9 \%$ & $13.5 \%$ & $8.9 \%$ & & \\
\hline \multirow[t]{2}{*}{7} & Hemoglobin electrophoresis & 98 & 100 & 32 & 29 & 3.03 & 0.98 \\
\hline & & $37.8 \%$ & $38.6 \%$ & $12.4 \%$ & $11.2 \%$ & & \\
\hline \multirow[t]{2}{*}{8} & Sphygmomanometer & 74 & 136 & 33 & 16 & 3.03 & 0.81 \\
\hline & & $28.6 \%$ & $52.5 \%$ & $12.7 \%$ & $6.2 \%$ & & \\
\hline \multirow[t]{2}{*}{9} & VCD & 90 & 107 & 38 & 24 & 3.02 & 0.93 \\
\hline & & $34.7 \%$ & $41.3 \%$ & $14.7 \%$ & $9.3 \%$ & & \\
\hline \multirow[t]{2}{*}{10} & Microscope & 38 & 198 & 11 & 12 & 3.01 & 0.61 \\
\hline & & $14.7 \%$ & $76.4 \%$ & $4.2 \%$ & $4.6 \%$ & & \\
\hline \multirow[t]{2}{*}{11} & DVD & 100 & 88 & 42 & 29 & 3.00 & 1.00 \\
\hline & & $38.6 \%$ & $34.0 \%$ & $16.2 \%$ & $11.2 \%$ & & \\
\hline \multirow[t]{2}{*}{12} & Orthoscopic & 72 & 136 & 30 & 21 & 3.00 & 0.85 \\
\hline & & $27.8 \%$ & $52.5 \%$ & $11.6 \%$ & $8.1 \%$ & & \\
\hline \multirow[t]{2}{*}{13} & CD ROM & 99 & 89 & 37 & 34 & 2.98 & 1.03 \\
\hline & & $38.2 \%$ & $34.4 \%$ & $14.3 \%$ & $13.1 \%$ & & \\
\hline \multirow[t]{2}{*}{14} & Glucometer & 80 & 114 & 44 & 21 & 2.98 & 0.90 \\
\hline & & $30.9 \%$ & $44.0 \%$ & $17.0 \%$ & $8.1 \%$ & & \\
\hline \multirow[t]{2}{*}{15} & Centrifuge machine & 73 & 134 & 23 & 29 & 2.97 & 0.91 \\
\hline & & $28.2 \%$ & $51.7 \%$ & $8.9 \%$ & $11.2 \%$ & & \\
\hline \multirow[t]{2}{*}{16} & Video & 90 & 102 & 30 & 37 & 2.95 & 1.02 \\
\hline & & $34.7 \%$ & $39.4 \%$ & $11.6 \%$ & $14.3 \%$ & & \\
\hline \multirow[t]{2}{*}{17} & Videoconferencing & 82 & 105 & 35 & 37 & 2.90 & 1.01 \\
\hline & & $31.7 \%$ & $40.5 \%$ & $13.5 \%$ & $14.3 \%$ & & \\
\hline \multirow[t]{2}{*}{18} & Projectors & 82 & 98 & 51 & 28 & 2.90 & 0.97 \\
\hline & & $31.7 \%$ & $37.8 \%$ & $19.7 \%$ & $10.8 \%$ & & \\
\hline \multirow[t]{2}{*}{19} & Computer system & 73 & 108 & 52 & 26 & 2.88 & 0.93 \\
\hline & & $28.2 \%$ & $41.7 \%$ & $20.1 \%$ & $10.0 \%$ & & \\
\hline \multirow[t]{2}{*}{20} & Telemedicine & 85 & 100 & 33 & 41 & 2.88 & 1.04 \\
\hline & & $32.8 \%$ & $38.6 \%$ & $12.7 \%$ & $15.8 \%$ & & \\
\hline \multirow[t]{2}{*}{21} & Radiograph & 67 & 82 & 90 & 20 & 2.76 & 0.93 \\
\hline & & $25.9 \%$ & $31.7 \%$ & $34.7 \%$ & $7.7 \%$ & & \\
\hline \multirow[t]{2}{*}{22} & Electronic BP Gauge & 86 & 78 & 30 & 65 & 2.71 & 1.17 \\
\hline & & $33.2 \%$ & $30.1 \%$ & $11.6 \%$ & $25.1 \%$ & & \\
\hline
\end{tabular}


KEY: HA=Highly Accessible, MA=Moderately Accessible, RA= Rarely Accessible, NH=Not Accessible

Table 8

Test of Norm showing the level of accessibility of health information tools for clinical decision making among clinical specialists in OAUTH

Table 8 showed the level of accessibility is $0.8 \%(\mathrm{n}=2)$ of the clinical specialists indicated that the health information tools were not accessible, $30.9 \%(\mathrm{n}=80)$ indicated moderately accessible and $68.3 \%(\mathrm{n}=177)$ indicated that the tools were highly accessible. Hence, it could be deduced that the level of accessibility in the study is high.

Table 8 level of accessibility of health information tools for clinical decision making among clinical specialists in OAUTH

\begin{tabular}{lllll} 
Interval & Level of accessibility & Frequency & Percentage & Mean index \\
\hline $1-29$ & Not accessible & 2 & 0.8 & \\
$30-58$ & Moderately accessible & 80 & 30.9 & \\
\hline $31-88$ & Highly accessible & 177 & 68.3 & $\mathbf{6 5 . 8 8 8 0}$
\end{tabular}

Research objective three: The frequency of accessibility to health information tools for clinical decision making among clinical specialists in OAUTH

Table 9 showed the frequency of accessibility of health information tools for clinical decision making among clinical specialists in OAUTH. It shows that ECG machine $(\bar{x}=3.84)$ ranked highest by the mean score rating and was followed in succession by $\operatorname{VCD}(\bar{x}=3.82)$, Internet $(\bar{x}=3.79)$ and Teleconferencing ( $\bar{x}=3.78)$. Orthoscopic $(\bar{x}=3.44)$ and Electronic BP Gauge $(\bar{x}=3.30)$ were the least items indicated by the respondents.

The inference drawn from the above result was that ECG machine, VCD, Internet, Teleconferencing, Telemedicine, Hemoglobin electrophoresis, GSM phones, Ipad, Ipod, Projectors, Videoconferencing, incubator, Video and DVD were the most frequently accessed health information tools for clinical decision making among clinical specialists in the study. The reason for this was because these were the items that ranked above the weighted mean of 3.62 set as the benchmark.

It was also found out from the focus group discussion that was held among the group of clinical specialists in 
OAUTH about the frequency of accessibility to health information tools, that health information tools such as ECG machine, hemoglobin electrophoresis and DVD for clinical decision making was high

The findings of the study also showed that clinical specialists in the study area indicated that the health information tools for clinical decision making is frequently accessible. The result of this study was in agreement with Anderson, Panos and Spencher (2004) who stated that access to information is an essential condition for development and empowerment. Accessibility to health information is seen in relation to nearness, ease of use and opportunities for interaction with people and other agencies while proximity and physical distance to a source or channel have been found to be factors influencing use of information. The aftereffect of the investigation verified Aguolu and Aguolu (2002) who expressed that endeavors are being made worldwide to elevate admittance to data, they anyway mourn the orderly highlights of underdevelopment, for example, power disappointment, machine breakdowns, and absence of extra parts and experts, which discontinuously slow down the presentation of current contraptions of data stockpiling and move in agricultural nations. The findings agreed with Nuq (2012) who with an early example of the difficulties in articulating information accessibility identified six components of information access, which are identification, availability, price (to the users), cost (to the provider), understanding (awareness), and acceptability. Similarly, Gans, Kralweki, Hammons and Dowd (2005) presents four elements of information accessibility, which are channel, nearness, cost and literacy level

Table 9 Frequency of accessibility of health information tools for clinical decision making among clinical specialists in OAUTH

\begin{tabular}{lllllllll} 
S/n & $\begin{array}{l}\text { Health Information } \\
\text { tools }\end{array}$ & Daily & Weekly & Monthly & Occasionally & Never & $\bar{x}$ & S.D \\
\hline 1 & ECG machine & 45 & 154 & 41 & 12 & 7 & 3.84 & 0.86 \\
& & $17.4 \%$ & $59.5 \%$ & $15.8 \%$ & $4.6 \%$ & $2.7 \%$ & & \\
2 & VCD & 94 & 86 & 35 & 26 & 18 & 3.82 & 1.22 \\
& & $36.3 \%$ & $33.2 \%$ & $13.5 \%$ & $10.0 \%$ & $6.9 \%$ & & \\
3 & Internet & 84 & 94 & 41 & 22 & 18 & 3.79 & 1.19 \\
& & $32.4 \%$ & $36.3 \%$ & $15.8 \%$ & $8.5 \%$ & $6.9 \%$ & & \\
4 & Teleconferencing & 103 & 66 & 39 & 31 & 20 & 3.78 & 1.30 \\
& & $39.8 \%$ & $25.5 \%$ & $15.1 \%$ & $12.0 \%$ & $7.7 \%$ & & \\
5 & Telemedicine & 80 & 98 & 36 & 32 & 13 & 3.77 & 1.16 \\
& & $30.9 \%$ & $37.8 \%$ & $13.9 \%$ & $12.4 \%$ & $5.0 \%$ & & \\
6 & Hemoglobin & 83 & 85 & 46 & 27 & 18 & 3.73 & 1.21 \\
& electrophoresis & $32.0 \%$ & $32.8 \%$ & $17.8 \%$ & $10.4 \%$ & $6.9 \%$ & & \\
7 & GSM phones,I pad, I & 81 & 82 & 53 & 21 & 22 & 3.69 & 1.23 \\
& pod & $31.3 \%$ & $31.7 \%$ & $20.5 \%$ & $8.1 \%$ & $8.5 \%$ & & \multirow{2}{*}{1.25} \\
8 & Projectors & 88 & 75 & 41 & 39 & 16 & 3.69 & 1.25 \\
& & $34.0 \%$ & $29.0 \%$ & $15.8 \%$ & $15.1 \%$ & $6.2 \%$ & & \\
9 & Videoconferencing & 77 & 99 & 28 & 34 & 21 & 3.68 & 1.25 \\
& & $29.7 \%$ & $38.2 \%$ & $10.8 \%$ & $13.1 \%$ & $8.1 \%$ & &
\end{tabular}




\begin{tabular}{|c|c|c|c|c|c|c|c|c|}
\hline \multirow[t]{2}{*}{10} & Incubator & 76 & 90 & 42 & 30 & 21 & 3.66 & 1.24 \\
\hline & & $29.3 \%$ & $34.7 \%$ & $16.2 \%$ & $11.6 \%$ & $8.1 \%$ & & \\
\hline \multirow[t]{2}{*}{11} & Video & 68 & 101 & 42 & 26 & 22 & 3.64 & 1.21 \\
\hline & & $26.3 \%$ & $39.0 \%$ & $16.2 \%$ & $10.0 \%$ & $8.5 \%$ & & \\
\hline \multirow[t]{2}{*}{12} & DVD & 73 & 92 & 42 & 33 & 19 & 3.64 & 1.22 \\
\hline & & $28.2 \%$ & $35.5 \%$ & $16.2 \%$ & $12.7 \%$ & $7.3 \%$ & & \\
\hline \multirow[t]{2}{*}{13} & Autoclave & 61 & 102 & 46 & 35 & 15 & 3.61 & 1.15 \\
\hline & & $23.6 \%$ & $39.4 \%$ & $17.8 \%$ & $13.5 \%$ & $5.8 \%$ & & \\
\hline \multirow[t]{2}{*}{14} & CD ROM & 83 & 68 & 47 & 44 & 17 & 3.60 & 1.27 \\
\hline & & $32.0 \%$ & $26.3 \%$ & $18.1 \%$ & $17.0 \%$ & $6.6 \%$ & & \\
\hline \multirow[t]{2}{*}{15} & Sphygmomanometer & 51 & 91 & 72 & 31 & 14 & 3.52 & 1.10 \\
\hline & & $19.7 \%$ & $35.1 \%$ & $27.8 \%$ & $12.0 \%$ & $5.4 \%$ & & \\
\hline \multirow[t]{2}{*}{16} & CT Scan & 34 & 84 & 119 & 18 & 4 & 3.49 & 0.86 \\
\hline & & $13.1 \%$ & $32.4 \%$ & $45.9 \%$ & $6.9 \%$ & $1.5 \%$ & & \\
\hline \multirow[t]{2}{*}{17} & Glucometer & 66 & 70 & 68 & 35 & 20 & 3.49 & 1.22 \\
\hline & & $25.5 \%$ & $27.0 \%$ & $26.3 \%$ & $13.5 \%$ & $7.7 \%$ & & \\
\hline \multirow[t]{2}{*}{18} & Microscope & 57 & 74 & 75 & 36 & 17 & 3.46 & 1.17 \\
\hline & & $22.0 \%$ & $28.6 \%$ & $29.0 \%$ & $13.9 \%$ & $6.6 \%$ & & \\
\hline \multirow[t]{2}{*}{19} & Radiograph & 74 & 60 & 43 & 73 & 9 & 3.45 & 1.26 \\
\hline & & $28.6 \%$ & $23.2 \%$ & $16.6 \%$ & $28.2 \%$ & $3.5 \%$ & & \\
\hline \multirow[t]{2}{*}{20} & Computer system & 61 & 85 & 41 & 50 & 22 & 3.44 & 1.27 \\
\hline & & $23.6 \%$ & $32.8 \%$ & $15.8 \%$ & $19.3 \%$ & $8.5 \%$ & & \\
\hline \multirow[t]{2}{*}{21} & Orthoscopic & 52 & 84 & 70 & 33 & 20 & 3.44 & 1.17 \\
\hline & & $20.1 \%$ & $32.4 \%$ & $27.0 \%$ & $12.7 \%$ & $7.7 \%$ & & \\
\hline \multirow[t]{2}{*}{22} & Electronic BP Gauge & 72 & 75 & 27 & 29 & 56 & 3.30 & 1.52 \\
\hline & & $27.8 \%$ & $29.0 \%$ & $10.4 \%$ & $11.2 \%$ & $21.6 \%$ & & \\
\hline
\end{tabular}

Weighted mean $=3.62$

Key: D=Daily, W= Weekly, M=Monthly, $O=$ Occasionally, $N=$ Never

Table 10 Test of Norm showing the frequency of accessibility of health information tools for clinical decision making among clinical specialists in OAUTH

Table 10 showed the frequency of accessibility to health information tools for clinical decision making among clinical specialists in OAUTH. $0.8 \%(\mathrm{n}=2)$ of the Clinical specialists indicated that the tools were less accessible, 26.6\% ( $n=69)$ indicated that the tools were moderately accessible and $72.6 \%(n=188)$ indicated that the tools were frequently accessible. Hence, it could be deduced that the clinical specialists in the study indicated that the health information tools for clinical decision making is frequently accessible. 
Table 10 showing the frequency of accessibility of health information tools for clinical decision making among clinical specialists in OAUTH

\begin{tabular}{lllll} 
Interval & Frequency of accessibility & Frequency & Percentage & Mean index \\
\hline $1-36$ & Less accessible & 2 & 0.8 & \\
$37-72$ & Moderately accessible & 69 & 26.6 & \\
\hline $73-110$ & Frequently accessible & 188 & 72.6 & $\mathbf{7 9 . 5 3 6 7}$
\end{tabular}

\section{Research objective four: The extent of use of health information tools for clinical decision making among clinical specialists in OAUTH}

Table 11 indicated the degree of usage of wellbeing data instruments for clinical dynamic among clinical experts in OAUTH. It shows that CT Scan $(\bar{x}=3.47)$ positioned most elevated by the mean score rating and was continued in progression by ECG machine $(\bar{x}=3.12)$, VCD $(\bar{x}=3.08)$ and DVD (3.07). Electronic BP Gauge $(\bar{x}=2.90)$ and Teleconferencing $(\bar{x}=2.85)$ were the least things showed by the respondents.

The surmising drawn from this utilizing the weighted mean of 3.01 is that CT Scan, ECG machine, VCD, DVD, Autoclave, Glucometer, hatchery, Hemoglobin electrophoresis and telemedicine were the most profoundly used wellbeing data instruments for clinical dynamic among clinical experts in OAUTH.

The examination additionally discovered from the FGD that was held among the gathering of clinical experts in OAUTH that wellbeing data apparatuses that were exceptionally used by the clinical experts in their dynamic incorporate CT check, DVD, projectors and telemedicine among others.

The ramifications of this is that the degree of utilization of wellbeing data devices for clinical dynamic among clinical experts in OAUTH is high and the example of utilization is consistently. The outcome upheld Federal Medical Department (2005) which obviously expressed that precise, convenient and important utilization of wellbeing data instruments in the medical services area is the basic advance toward advancing general wellbeing and proof based medication. As a result, there is a need for adequate provision and availability of necessary health information tools that will strengthen the healthcare in Nigeria. The findings of the study also supported Sackett et al., (2000) who stated that demographic and biographic variables, such as age, clinical experience, and levels of educational attainment, were poor predictors of how useful an information source would be to the health workers. 
Table 11 Utilisation of health information tools for clinical decision making among clinical specialists in OAUTH

\begin{tabular}{|c|c|c|c|c|c|c|c|}
\hline $\mathbf{s} / \mathbf{n}$ & Health Information tools & HU & MU & $\mathbf{U}$ & NU & $\bar{x}$ & S.D \\
\hline \multirow[t]{2}{*}{1} & CT Scan & 146 & 92 & 18 & & 3.47 & 0.68 \\
\hline & & $56.4 \%$ & $35.5 \%$ & $6.9 \%$ & $1.2 \%$ & & \\
\hline \multirow[t]{2}{*}{2} & ECG machine & 79 & 137 & 37 & 6 & 3.12 & 0.73 \\
\hline & & $30.5 \%$ & $52.9 \%$ & $14.3 \%$ & $2.3 \%$ & & \\
\hline \multirow[t]{2}{*}{3} & VCD & 107 & 91 & 35 & 26 & 3.08 & 0.97 \\
\hline & & $41.3 \%$ & $35.1 \%$ & $13.5 \%$ & $10.0 \%$ & & \\
\hline \multirow[t]{2}{*}{4} & DVD & 97 & 104 & 37 & 21 & 3.07 & 0.92 \\
\hline & & $37.5 \%$ & $40.2 \%$ & $14.3 \%$ & $8.1 \%$ & & \\
\hline \multirow[t]{2}{*}{5} & Autoclave & 87 & 123 & 29 & 20 & 3.07 & 0.87 \\
\hline & & $33.6 \%$ & $47.5 \%$ & $11.2 \%$ & $7.7 \%$ & & \\
\hline \multirow[t]{2}{*}{6} & Glucometer & 92 & 114 & 32 & 21 & 3.07 & 0.90 \\
\hline & & $35.5 \%$ & $44.0 \%$ & $12.4 \%$ & $8.1 \%$ & & \\
\hline \multirow[t]{2}{*}{7} & Incubator & 92 & 113 & 29 & 25 & 3.05 & 0.92 \\
\hline & & $35.5 \%$ & $43.6 \%$ & $11.2 \%$ & $9.7 \%$ & & \\
\hline \multirow[t]{2}{*}{8} & Hemoglobin electrophoresis & 88 & 114 & 36 & 21 & 3.04 & 0.90 \\
\hline & & $34.0 \%$ & $44.0 \%$ & $13.9 \%$ & $8.1 \%$ & & \\
\hline \multirow[t]{2}{*}{9} & Telemedicine & 96 & 96 & 45 & 22 & 3.03 & 0.94 \\
\hline & & $37.1 \%$ & $37.1 \%$ & $17.4 \%$ & $8.5 \%$ & & \\
\hline \multirow[t]{2}{*}{10} & GSM phones, ipad, ipod & 96 & 94 & 44 & 25 & 3.01 & 0.96 \\
\hline & & $37.1 \%$ & $36.3 \%$ & $17.0 \%$ & $9.7 \%$ & & \\
\hline \multirow[t]{2}{*}{11} & Internet & 83 & 117 & 35 & 24 & 3.00 & 0.91 \\
\hline & & $32.0 \%$ & $45.2 \%$ & $13.5 \%$ & $9.3 \%$ & & \\
\hline \multirow[t]{2}{*}{12} & Video & 87 & 109 & 37 & 26 & 2.99 & 0.94 \\
\hline & & $33.6 \%$ & $42.1 \%$ & $14.3 \%$ & $10.0 \%$ & & \\
\hline \multirow[t]{2}{*}{13} & Radiograph & 93 & 92 & 42 & 32 & 2.95 & 1.01 \\
\hline & & $35.9 \%$ & $35.5 \%$ & $16.2 \%$ & $12.4 \%$ & & \\
\hline \multirow[t]{2}{*}{14} & Computer system & 86 & 107 & 34 & 32 & 2.95 & 0.98 \\
\hline & & $33.2 \%$ & $41.3 \%$ & $13.1 \%$ & $12.4 \%$ & & \\
\hline \multirow[t]{2}{*}{15} & CD ROM & 83 & 111 & 34 & 31 & 2.95 & 0.97 \\
\hline & & $32.0 \%$ & $42.9 \%$ & $13.1 \%$ & $12.0 \%$ & & \\
\hline \multirow[t]{2}{*}{16} & Orthoscopic & 75 & 124 & 33 & 27 & 2.95 & 0.91 \\
\hline & & $29.0 \%$ & $47.9 \%$ & $12.7 \%$ & $10.4 \%$ & & \\
\hline \multirow[t]{2}{*}{17} & Sphygmomanometer & 73 & 123 & 39 & 24 & 2.95 & 0.90 \\
\hline & & $28.2 \%$ & $47.5 \%$ & $15.1 \%$ & $9.3 \%$ & & \\
\hline \multirow[t]{2}{*}{18} & Microscope & 86 & 112 & 44 & 17 & 2.95 & 0.91 \\
\hline & & $33.2 \%$ & $43.2 \%$ & $17.0 \%$ & $6.6 \%$ & & \\
\hline \multirow[t]{2}{*}{19} & Projectors & 76 & 115 & 43 & 25 & 2.93 & 0.92 \\
\hline & & $29.3 \%$ & $44.4 \%$ & $16.6 \%$ & $9.7 \%$ & & \\
\hline \multirow[t]{2}{*}{20} & Videoconferencing & 80 & 104 & 47 & 28 & 2.91 & 0.96 \\
\hline & & $30.9 \%$ & $40.2 \%$ & $18.1 \%$ & $10.8 \%$ & & \\
\hline \multirow[t]{2}{*}{21} & Electronic BP Gauge & 84 & 98 & 43 & 34 & 2.90 & 1.00 \\
\hline & & $32.4 \%$ & $37.8 \%$ & $16.6 \%$ & $13.1 \%$ & & \\
\hline \multirow[t]{2}{*}{22} & Teleconferencing & 84 & 92 & 44 & 39 & 2.85 & 1.04 \\
\hline & & $32.4 \%$ & $35.5 \%$ & $17.0 \%$ & $15.1 \%$ & & \\
\hline
\end{tabular}


KEY: HU=Highly Utilised, MU=Moderately Utilised, U= Utilised, NU=NOT Utilised

Table 12

Test of Norm showing the extent of use of health information tools for clinical decision making among clinical specialists in OAUTH

Table 12 showed the extent of use of health information tools for clinical decision making among clinical specialists in OAUTH. $0.8 \%(n=2)$ of the Clinical specialists indicated low extent of use, 26.6\% $(n=69)$ indicated moderate extent of use and $72.6 \%(n=188)$ indicated high use of health information tools for clinical decision making among clinical specialists. Hence, it could be deduced from the test of norm that the extent of use of health information tools for clinical decision making among clinical specialists in OAUTH is high. 
Table 12 The extent of use of health information tools for clinical decision making among clinical specialists in OAUTH

\begin{tabular}{lllll} 
Interval & Extent of use & Frequency & Percentage & Mean index \\
\hline $1-29$ & Low & 2 & 0.8 & \\
$30-58$ & Moderate & 69 & 26.6 & \\
\hline $59-88$ & High & 188 & 72.6 & $\mathbf{6 6 . 3 6 6 8}$
\end{tabular}

\section{Research objective five: The frequency of use of health information tools for clinical decision making among clinical specialists in OAUTH}

Table 13 indicated the recurrence of utilization of wellbeing data instruments for clinical dynamic among clinical experts in OAUTH. It shows that CT Scan $(\bar{x}=3.85)$ positioned most elevated by the mean score rating and was continued in progression by ECG machine (3.73), web ( 3.62) and GSM telephones, ipad, ipod $(\bar{x}=3.60)$. Sphygmomanometer $(\bar{x}=3.31)$ and Microscope $(\bar{x}=3.29)$ were the least things showed by the respondents.

The surmising drawn from this, utilizing the weighted mean of $\bar{x}=3.50$ was that CT Scan, ECG machine, Internet, GSM telephones, ipad, ipod, Telemedicine, DVD, Computer framework, Electronic BP Gauge, Teleconferencing were the most often utilized wellbeing data instruments for clinical dynamic among clinical experts in OAUTH. The investigation likewise discovered from the center gathering conversation that was held among the gathering of clinical experts in OAUTH about the recurrence of use of wellbeing data devices that wellbeing data devices, for example, CT filter, ECG machine, telemedicine were habitually utilized on week by week reason for clinical dynamic. The outcome demonstrated that the recurrence of utilization of wellbeing data devices for clinical dynamic among clinical experts in OAUTH was high and the example of utilization was consistently. The discoveries concurred with Schilling (2012) who expressed that data use as a cycle that is gone before by data chasing and that data is helpful just if such is considered esteemed and is retained, to take care of an issue or sort out a circumstance. The outcome additionally certified Gans, Kralweki, Hammons and Dowd (2005) who expressed that for data to be utilized, it ought to contain minimal measure of detail predictable with viable dynamic. 
Table 13 Frequency of use of health information tools for clinical decision making among clinical specialists in OAUTH

\begin{tabular}{|c|c|c|c|c|c|c|c|c|}
\hline $\mathbf{s} / \mathbf{n}$ & $\begin{array}{l}\text { Health Information } \\
\text { tools }\end{array}$ & Daily & Weekly & Monthly & Occas. & Never & $\bar{x}$ & S.D \\
\hline \multirow[t]{2}{*}{1} & CT Scan & 88 & 82 & 63 & 14 & 12 & 3.85 & 1.09 \\
\hline & & $34.0 \%$ & $31.7 \%$ & $24.3 \%$ & $5.4 \%$ & $4.6 \%$ & & \\
\hline \multirow[t]{2}{*}{2} & ECG machine & 74 & 105 & 35 & 27 & 18 & 3.73 & 1.18 \\
\hline & & $28.6 \%$ & $40.5 \%$ & $13.5 \%$ & $10.4 \%$ & $6.9 \%$ & & \\
\hline \multirow[t]{2}{*}{3} & Internet & 69 & 87 & 61 & 20 & 22 & 3.62 & 1.20 \\
\hline & & $26.6 \%$ & $33.6 \%$ & $23.6 \%$ & $7.7 \%$ & $8.5 \%$ & & \\
\hline \multirow[t]{2}{*}{4} & GSM phones, I pad, I & 73 & 91 & 37 & 34 & 24 & 3.60 & 1.28 \\
\hline & pod & $28.2 \%$ & $35.1 \%$ & $14.3 \%$ & $13.1 \%$ & $9.3 \%$ & & \\
\hline \multirow[t]{2}{*}{5} & Telemedicine & 60 & 113 & 35 & 24 & 27 & 3.60 & 1.23 \\
\hline & & $23.2 \%$ & $43.6 \%$ & $13.5 \%$ & $9.3 \%$ & $10.4 \%$ & & \\
\hline \multirow[t]{2}{*}{6} & DVD & 65 & 89 & 56 & 27 & 22 & 3.57 & 1.21 \\
\hline & & $25.1 \%$ & $34.4 \%$ & $21.6 \%$ & $10.4 \%$ & $8.5 \%$ & & \\
\hline \multirow[t]{2}{*}{7} & Computer system & 67 & 91 & 46 & 31 & 24 & 3.56 & 1.25 \\
\hline & & $25.9 \%$ & $35.1 \%$ & $17.8 \%$ & $12.0 \%$ & $9.3 \%$ & & \\
\hline \multirow[t]{2}{*}{8} & Electronic BP Gauge & 80 & 80 & 38 & 24 & 37 & 3.55 & 1.38 \\
\hline & & $30.9 \%$ & $30.9 \%$ & $14.7 \%$ & $9.3 \%$ & $14.3 \%$ & & \\
\hline \multirow[t]{2}{*}{9} & Teleconferencing & 64 & 88 & 52 & 28 & 27 & 3.52 & 1.26 \\
\hline & & $24.7 \%$ & $34.0 \%$ & $20.1 \%$ & $10.8 \%$ & $10.4 \%$ & & \\
\hline \multirow[t]{2}{*}{10} & Autoclave & 52 & 96 & 65 & 20 & 26 & 3.49 & 1.19 \\
\hline & & $20.1 \%$ & $37.1 \%$ & $25.1 \%$ & $7.7 \%$ & $10.0 \%$ & & \\
\hline \multirow[t]{2}{*}{11} & Video & 57 & 91 & 56 & 30 & 25 & 3.48 & 1.23 \\
\hline & & $22.0 \%$ & $35.1 \%$ & $21.6 \%$ & $11.6 \%$ & $9.7 \%$ & & \\
\hline \multirow[t]{2}{*}{12} & Incubator & 57 & 83 & 66 & 33 & 20 & 3.48 & 1.19 \\
\hline & & $22.0 \%$ & $32.0 \%$ & $25.5 \%$ & $12.7 \%$ & $7.7 \%$ & & \\
\hline \multirow[t]{2}{*}{13} & Glucometer & 52 & 83 & 78 & 29 & 17 & 3.48 & 1.13 \\
\hline & & $20.1 \%$ & $32.0 \%$ & $30.1 \%$ & $11.2 \%$ & $6.6 \%$ & & \\
\hline \multirow[t]{2}{*}{14} & Hemoglobin & 53 & 88 & 62 & 33 & 23 & 3.44 & 1.20 \\
\hline & electrophoresis & $20.5 \%$ & $34.0 \%$ & $23.9 \%$ & $12.7 \%$ & $8.9 \%$ & & \\
\hline \multirow[t]{2}{*}{15} & CD ROM & 59 & 80 & 58 & 36 & 26 & 3.42 & 1.26 \\
\hline & & $22.8 \%$ & $30.9 \%$ & $22.4 \%$ & $13.9 \%$ & $10.0 \%$ & & \\
\hline \multirow[t]{2}{*}{16} & Radiograph & 61 & 82 & 46 & 42 & 28 & 3.41 & 1.30 \\
\hline & & $23.6 \%$ & $31.7 \%$ & $17.8 \%$ & $16.2 \%$ & $10.8 \%$ & & \\
\hline \multirow[t]{2}{*}{17} & Projectors & 50 & 99 & 48 & 30 & 32 & 3.41 & 1.27 \\
\hline & & $19.3 \%$ & $38.2 \%$ & $18.5 \%$ & $11.6 \%$ & $12.4 \%$ & & \\
\hline \multirow[t]{2}{*}{18} & Videoconferencing & 52 & 90 & 50 & 35 & 32 & 3.37 & 1.29 \\
\hline & & $20.1 \%$ & $34.7 \%$ & $19.3 \%$ & $13.5 \%$ & $12.4 \%$ & & \\
\hline \multirow[t]{2}{*}{19} & VCD & 49 & 82 & 72 & 28 & 28 & 3.37 & 1.22 \\
\hline & & $18.9 \%$ & $31.7 \%$ & $27.8 \%$ & $10.8 \%$ & $10.8 \%$ & & \\
\hline \multirow[t]{2}{*}{20} & Orthoscopic & 35 & 90 & 88 & 27 & 19 & 3.37 & 1.08 \\
\hline & & $13.5 \%$ & $34.7 \%$ & $34.0 \%$ & $10.4 \%$ & $7.3 \%$ & & \\
\hline \multirow[t]{2}{*}{21} & Sphygmomanometer & 43 & 80 & 74 & 39 & 23 & 3.31 & 1.18 \\
\hline & & $16.6 \%$ & $30.9 \%$ & $28.6 \%$ & $15.1 \%$ & $8.9 \%$ & & \\
\hline 22 & Microscope & 30 & 95 & 84 & 20 & 30 & 3.29 & 1.14 \\
\hline
\end{tabular}


Key: $D=$ Daily, $W=$ Weekly, $M=$ Monthly, $O=$ Occasionally, $N=$ Never

Table 14 Test of Norm showing the frequency of use of health information tools for clinical decision making among clinical specialists in OAUTH

Table 14 showed the frequency of use is $3.9 \%(n=10)$ of the Clinical specialists indicated low frequency of use, $29.7 \%(n=77)$ indicated moderate frequency of use and $66.4 \%(n=172)$ indicated high. Hence, it could be deduced that the frequency of use was on a weekly basis. 
Table 14 showing the frequency of use of health information tools for clinical decision making among clinical specialists in OAUTH

\begin{tabular}{lllll} 
Interval & Frequency of use & Frequency & Percentage & Mean index \\
\hline $1-36$ & Low & 10 & 3.9 & \\
$37-72$ & Moderate & 77 & 29.7 & \\
\hline $73-110$ & High & 172 & 66.4 & $\mathbf{7 6 . 9 5 2 6}$
\end{tabular}

\section{Research objective six: The extent of use of various core skills of clinical decision making among clinical specialists in OAUTH}

Table 15 showed the utilisation of various core skills of clinical decision making among clinical specialists in OAUTH. It shows that Pattern recognition from experience $(\bar{x}=3.32)$ ranked highest by the mean score rating and was followed in succession by Critical thinking without emotion $(\bar{x}=3.16)$, Hypothesis updating $(\bar{x}=3.07)$ and Perception based confidence $(\bar{x}=2.97)$. Time pressure balance $(\bar{x}=2.88)$ and Evidencebased approaches $(\bar{x}=2.83$ ) were the least items indicated by the respondents.

The inference drawn from this result was that pattern recognition from experience, critical thinking without emotion and hypothesis updating were the major core skills of clinical decision making among clinical specialists in OAUTH.

This finding from the focus group discussion that was held among the group of clinical specialists in OAUTH that the major core skills a clinical professional should possess in making clinical decision include critical thinking without emotions and time pressure balance.

The findings revealed that the extent of use of various core skills in the study was very high. The result agreed with Timmermans and Mauck (2005) who stated that the sociology of being a medical professional, which holds physicians that have expert knowledge and clinical competence in high regard, might explain this behaviour. The result of the study also supported Hollander and Morano (2012) who stated that the act and perception of needing to seek knowledge may reflect negatively on a physician's competence and professionalism. In understanding the cognitive processes that complicate how physicians arrive at their decisions, one can see the role of confidence in clinical reasoning and information seeking behaviour. The results of the study corroborated Samuel, Wolf and Wagner (2010) who stated that clinical specialists who believe that their accumulated clinical knowledge is all they need to reach a correct decision will not be motivated to access external tools and may possibly be inflexible to change a planned management course when information in the evidence based medicine (EBM) literature that may be contrary to their belief is presented. The findings also agreed with Friedman and Jeremy (2005) who stated that to look at the connection among certainty and clinical finding precision and proposed four conditions of concordance or dissonance that rely upon the arrangement of certainty and rightness 
Table 16

Utilisation of various core skills of clinical decision making among clinical specialists in OAUTH

\begin{tabular}{|c|c|c|c|c|c|c|c|}
\hline $\mathbf{s} / \mathbf{n}$ & Core skills of clinical decision making & SA & $\mathbf{A}$ & D & SD & $\bar{x}$ & S.D \\
\hline \multirow[t]{2}{*}{1} & Pattern recognition from experience & 111 & 131 & 5 & 12 & 3.32 & 0.73 \\
\hline & & $42.9 \%$ & $50.6 \%$ & $1.9 \%$ & $4.6 \%$ & & \\
\hline \multirow[t]{2}{*}{2} & Critical thinking without emotion & 86 & 142 & 18 & 13 & 3.16 & 0.76 \\
\hline & & $33.2 \%$ & $54.8 \%$ & $6.9 \%$ & $5.0 \%$ & & \\
\hline \multirow[t]{2}{*}{3} & Hypothesis updating & 87 & 118 & 40 & 14 & 3.07 & 0.84 \\
\hline & & $33.6 \%$ & $45.6 \%$ & $15.4 \%$ & $5.4 \%$ & & \\
\hline \multirow[t]{2}{*}{4} & Perception based confidence & 81 & 117 & 34 & 27 & 2.97 & 0.93 \\
\hline & & $31.3 \%$ & $45.2 \%$ & $13.1 \%$ & $10.4 \%$ & & \\
\hline \multirow[t]{2}{*}{5} & Proactive decision making & 72 & 127 & 37 & 23 & 2.96 & 0.88 \\
\hline & & $27.8 \%$ & $49.0 \%$ & $14.3 \%$ & $8.9 \%$ & & \\
\hline \multirow[t]{2}{*}{6} & Overcoming environment task complexity & 69 & 129 & 42 & 19 & 2.96 & 0.85 \\
\hline & & $26.6 \%$ & $49.8 \%$ & $16.2 \%$ & $7.3 \%$ & & \\
\hline \multirow[t]{2}{*}{7} & Teamwork using gathered evidence from & 89 & 100 & 38 & 32 & 2.95 & 0.99 \\
\hline & colleagues & $34.4 \%$ & $38.6 \%$ & $14.7 \%$ & $12.4 \%$ & & \\
\hline \multirow[t]{2}{*}{8} & Reflection using feedback from others & 75 & 121 & 35 & 28 & 2.94 & 0.93 \\
\hline & & $29.0 \%$ & $46.7 \%$ & $13.5 \%$ & $10.8 \%$ & & \\
\hline \multirow[t]{2}{*}{9} & Age and educational level & 81 & 106 & 46 & 26 & 2.93 & 0.94 \\
\hline & & $31.3 \%$ & $40.9 \%$ & $17.8 \%$ & $10.0 \%$ & & \\
\hline \multirow[t]{2}{*}{10} & Communication skills from active listening & 80 & 106 & 45 & 28 & 2.92 & 0.95 \\
\hline & & $30.9 \%$ & $40.9 \%$ & $17.4 \%$ & $10.8 \%$ & & \\
\hline \multirow[t]{2}{*}{11} & Knowledge sharing among the professionals & 82 & 102 & 45 & 30 & 2.91 & 0.97 \\
\hline & & $31.7 \%$ & $39.4 \%$ & $17.4 \%$ & $11.6 \%$ & & \\
\hline \multirow[t]{2}{*}{12} & Time pressure balance & 70 & 111 & 56 & 22 & 2.88 & 0.90 \\
\hline & & $27.0 \%$ & $42.9 \%$ & $21.6 \%$ & $8.5 \%$ & & \\
\hline \multirow[t]{2}{*}{13} & Evidence-based approaches & 72 & 95 & 68 & 24 & 2.83 & 0.94 \\
\hline & & $27.8 \%$ & $36.7 \%$ & $26.3 \%$ & $9.3 \%$ & & \\
\hline
\end{tabular}

Weighted mean $=2.98$

Key: SD = Strongly Disagree, $A=$ Agree D = Disagree, SA = Strongly Disagree

Table 17 Test of Norm showing the extent of use of various core skills of clinical decision 
making among clinical specialists in OAUTH

Table 17 showed the extent of use of various core skills of clinical decision making among clinical specialists in OAUTH. $1.9 \%(n=5)$ of the Clinical specialists had low extent of use, $32.8 \%(n=85)$ had moderate extent of use and $65.3 \%(n=169)$ had high extent of use. Hence, it could be deduced that the extent of use of various core skills in the study is high.

Table 17 the showed the extent of use of various core skills of clinical decision making among clinical specialists in OAUTH

\begin{tabular}{lllll} 
Interval & Extent of use & Frequency & Percentage & Mean index \\
\hline $1-17$ & Low & 5 & 1.9 & \\
$18-35$ & Moderate & 85 & 32.8 & \\
\hline $36-52$ & High & 169 & 65.3 & $\mathbf{3 8 . 8 0 6 9}$
\end{tabular}

\section{Research objective seven: The challenges impeding clinical specialists in the use of health information tools for clinical decision making in OAUTH}

Table 18 demonstrated the difficulties hindering clinical experts in the utilization of wellbeing data assets for clinical dynamic in OAUTH. It shows that Unfavorable/conflicting government arrangements ( 3.15) positioned most noteworthy by the mean score rating and was continued in progression by "Socio-economic status of clinical specialists $(\bar{x}=3.14$ ), lack of adequate funding ( $\bar{x}=2.98$ ), lack of trained personnel in health information services delivery $(\bar{x}=2.95)$, health information sources are not easily accessible $(\bar{x}=2.94)$ and poor packaging of health information services $(\bar{x}=2.93)$. Cultural values and traditions $(\bar{x}=2.73)$ and level of education/knowledge-base" $(\bar{x}=2.72)$ were the least item indicated by the respondents using the weighted mean of 2.89 as benchmark.

The surmising drawn from the above outcome was that negative/conflicting government approaches, financial status of clinical subject matter experts, absence of satisfactory subsidizing, absence of prepared faculty in wellbeing data administrations conveyance, wellbeing data sources are not effectively open, helpless bundling of wellbeing data administrations, absence of heath data education among the clinical subject matter experts and absence of sufficient expert abilities were the significant difficulties obstructing clinical experts in the utilization of wellbeing data assets for clinical dynamic in the examination region. The investigation additionally discovered from the center gathering conversation that was held among the gathering of clinical experts in OAUTH that the difficulties blocking clinical experts clinical dynamic incorporate absence of sufficient financing, absence of prepared staff, financial status of clinical trained professionals, strict and social convictions. Another finding additionally demonstrated that financial status of clinical experts was one of the difficulties blocking clinical experts in the utilization of wellbeing data 
assets for clinical dynamic. This finding was couple with Adeyoyin and Oyewusi (2015) discovering who additionally found that financial status of clinical experts as far as absence of assets militates against their buying power and thusly influenced their wellbeing data assets use. The finding was also in agreement with Samuelson Carter and Ruggels (2013) who revealed that socio-economic class has been found to have distinct effects upon consumption. Poor packaging of health information tools services delivery was also found to have been a challenge. Hence the need for repackaging health information services, information repackaging which can be seen as information consolidation, according to Culver, Romano, Randall and Stafford (2011) is defined as a text message purposefully structured from existing public knowledge from the original accounts or in the original structure and form. According to them, the consolidation process starts with the critical study of potential users, choice of primary information tools and the assessment of their intellectual contents. Health professional can package and repackage health information services in oral, textual and electronic media for better use of clinical specialists. Other challenges including lack of adequate funding, Hafkin and Taggart (2010) noted that poor funding poses serious challenges to health information access and use. Reduction in budgetary allocation to the health sector in Nigeria is a constraint in the provision of health information tools and tools . Literacy, which is defined by Oxford English dictionary (OED 2003) as the individuals' ability to read and write; a person's facility with or knowledge about a particular topic (Aramide, Oduroye and Alagbe, 2013). They further opine that literacy level of information users rely on users' ability to function in a particular context that requires some background knowledge about information. Jacobs, Amuta and Jeon (2017) conclude that literacy level affects the attitudinal and behavioural patterns of individuals. This implies that clinical specialists with high information literacy level can read, understand and act on any information obtained while those with limited information literacy skills are likely to have problems in interpreting the contents of information materials (Watts and Ibegbulam 2006). Aspinall, Good, Glassman and Valentino (2008) concludes that literacy includes not only the ability to read, but the complexity of information understood, accessed and acted upon. 
Table 18 Challenges impeding clinical specialists in the use of health information tools for clinical decision making in OAUTH

\begin{tabular}{|c|c|c|c|c|c|c|c|}
\hline $\mathbf{s} / \mathbf{n}$ & $\begin{array}{l}\text { Challenges impeding clinical decision } \\
\text { making }\end{array}$ & SA & $\mathbf{A}$ & D & SD & $\bar{x}$ & S.D \\
\hline 1 & Negative/conflicting government strategies & 69 & 169 & 12 & 9 & 3.15 & 0.66 \\
\hline 2 & Socio-economic status of clinical specialists & $\begin{array}{l}26.6 \% \\
92 \\
35.5 \%\end{array}$ & $\begin{array}{l}65.3 \% \\
123 \\
47.5 \%\end{array}$ & $\begin{array}{l}4.6 \% \\
33 \\
12.7 \%\end{array}$ & $\begin{array}{l}3.5 \% \\
11 \\
4.2 \%\end{array}$ & 3.14 & 0.80 \\
\hline 3 & Lack of adequate funding & $\begin{array}{l}76 \\
29.3 \%\end{array}$ & $\begin{array}{l}121 \\
46.7 \%\end{array}$ & $\begin{array}{l}4 \\
17.0 \%\end{array}$ & $\begin{array}{l}18 \\
6.9 \%\end{array}$ & 2.98 & 0.86 \\
\hline 4 & $\begin{array}{l}\text { Lack of trained personnel in health } \\
\text { information services delivery }\end{array}$ & $\begin{array}{l}69 \\
26.6 \%\end{array}$ & $\begin{array}{l}128 \\
49.4 \%\end{array}$ & $\begin{array}{l}42 \\
16.2 \%\end{array}$ & $\begin{array}{l}20 \\
7.7 \%\end{array}$ & 2.95 & 0.86 \\
\hline 5 & $\begin{array}{l}\text { Health information sources are not easily } \\
\text { accessible }\end{array}$ & $\begin{array}{l}82 \\
31.7 \%\end{array}$ & $\begin{array}{l}109 \\
42.1 \%\end{array}$ & $\begin{array}{l}38 \\
14.7 \%\end{array}$ & $\begin{array}{l}30 \\
11.6 \%\end{array}$ & 2.94 & 0.96 \\
\hline 6 & Poor packaging of health information services & $\begin{array}{l}62 \\
23.9 \%\end{array}$ & $\begin{array}{l}132 \\
51.0 \%\end{array}$ & $\begin{array}{l}49 \\
18.9 \%\end{array}$ & $\begin{array}{l}16 \\
6.2 \%\end{array}$ & 2.93 & 0.82 \\
\hline 7 & $\begin{array}{l}\text { Lack of heath information literacy among the } \\
\text { clinical specialists }\end{array}$ & $\begin{array}{l}79 \\
30.5 \%\end{array}$ & $\begin{array}{l}110 \\
42.5 \%\end{array}$ & $\begin{array}{l}38 \\
14.7 \%\end{array}$ & $\begin{array}{l}32 \\
12.4 \%\end{array}$ & 2.91 & 0.97 \\
\hline 8 & Lack of adequate professional skills & $\begin{array}{l}75 \\
29.0 \%\end{array}$ & $\begin{array}{l}111 \\
42.9 \%\end{array}$ & $\begin{array}{l}46 \\
17.8 \%\end{array}$ & $\begin{array}{l}27 \\
10.4 \%\end{array}$ & 2.90 & 0.94 \\
\hline 9 & $\begin{array}{l}\text { Health information managers are not } \\
\text { accommodating }\end{array}$ & $\begin{array}{l}69 \\
26.6 \%\end{array}$ & $\begin{array}{l}114 \\
44.0 \%\end{array}$ & $\begin{array}{l}46 \\
17.8 \%\end{array}$ & $\begin{array}{l}30 \\
11.6 \%\end{array}$ & 2.86 & 0.94 \\
\hline 10 & Religious beliefs & $\begin{array}{l}79 \\
30.5 \%\end{array}$ & $\begin{array}{l}87 \\
33.6 \%\end{array}$ & $\begin{array}{l}57 \\
22.0 \%\end{array}$ & $\begin{array}{l}36 \\
13.9 \%\end{array}$ & 2.81 & 1.02 \\
\hline 11 & $\begin{array}{l}\text { Health information provided are sometimes } \\
\text { not current }\end{array}$ & $\begin{array}{l}70 \\
27.0 \%\end{array}$ & $\begin{array}{l}96 \\
37.1 \%\end{array}$ & $\begin{array}{l}64 \\
24.7 \%\end{array}$ & $\begin{array}{l}29 \\
11.2 \%\end{array}$ & 2.80 & 0.96 \\
\hline 12 & Health information delivery are not timely & $\begin{array}{l}56 \\
21.6 \%\end{array}$ & $\begin{array}{l}119 \\
45.9 \%\end{array}$ & $\begin{array}{l}58 \\
22.4 \%\end{array}$ & $\begin{array}{l}26 \\
10.0 \%\end{array}$ & 2.79 & 0.90 \\
\hline 13 & Health information are not readily available & $\begin{array}{l}82 \\
31.7 \%\end{array}$ & $\begin{array}{l}109 \\
42.1 \%\end{array}$ & $\begin{array}{l}51 \\
19.7 \%\end{array}$ & $\begin{array}{l}38 \\
14.7 \%\end{array}$ & 2.75 & 0.98 \\
\hline 14 & Cultural values and traditions & $\begin{array}{l}72 \\
27.8 \%\end{array}$ & $\begin{array}{l}85 \\
32.8 \%\end{array}$ & $\begin{array}{l}61 \\
23.6 \%\end{array}$ & $\begin{array}{l}41 \\
15.8 \%\end{array}$ & 2.73 & 1.04 \\
\hline 15 & Level of education/knowledgebase & $\begin{array}{l}55 \\
21.2 \% \\
\end{array}$ & $\begin{array}{l}108 \\
41.7 \% \\
\end{array}$ & $\begin{array}{l}65 \\
25.1 \% \\
\end{array}$ & $\begin{array}{l}31 \\
12.0 \%\end{array}$ & 2.72 & 0.93 \\
\hline
\end{tabular}

Weighted mean $=2.89$

Key: SD = Strongly Disagree, $A$ = Agree $D=$ Disagree, $S A=$ Strongly Disagree 


\section{Research hypotheses:}

Hypothesis one: There is no significant relationship between access to health information tools (HIR) and clinical decision making among clinical specialists in OAUTH

Table 19 showed that there is significant relationship between access to health information tools and clinical decision making among clinical specialists in OAUTH $(r=.347, \mathrm{n}=259, \mathrm{P}(.000)<0.05)$. The hypothesis was therefore rejected.

The finding was in tandem with Kahane (2011) who opined that health Information accessibility refers to the ease with which clinical specialists acquire the right information from available sources to solve the problems encountered during clinical decision-making. Accessibility to health information is seen in relation to nearness, ease of use and opportunities for interaction with people and other agencies while proximity and physical distance to a source or channel have been found to be factors influencing use of information.

Table 19 Pearson Product Moment Correlation (PPMC) showing the relationship between access to health information tools (HIR) and clinical decision making among clinical specialists in OAUTH

\begin{tabular}{lllllll} 
Variable & Mean & Std. Dev. & N & r & P-value & Remark \\
\hline Access to HIR & 138.8996 & 20.8815 & & & & Sig.
\end{tabular}

* Sig. at 0.05 level 
Hypothesis two: There is no significant relationship between use of health information tools (HIR) and clinical decision making among clinical specialists in OAUTH

Table 20 showed that there is significant relationship between use of health information tools and clinical decision making among clinical specialists in OAUTH $(\mathrm{r}=.352, \mathrm{n}=259, \mathrm{P}(.000)<0.05)$.

The hypothesis was therefore rejected.

The outcome validated Karl (2007) who expressed that conceptualized data utilize two classifications of results of data to speak to the data use as the dynamic results and its impact, which is the data in the movement. Data use is a dynamic, intelligent social cycle of bringing about that, which may bring about development of significance or dynamic (Choo 2007).

Table 20 Pearson Product Moment Correlation (PPMC) showing the relationship between use of health information tools (HIR) and clinical decision making among clinical specialists in OAUTH

\begin{tabular}{lllllll} 
Variable & Mean & Std. Dev. & N & r & P-value & Remark \\
\hline Use of HIR & 143.1969 & 25.2629 & & & & Sig.
\end{tabular}

* Sig. at 0.05 level

Hypothesis Three: There is no significant joint contribution of access and use of health information tools to clinical decision making among clinical specialists in OAUTH

Table 21 showed the joint contribution of access and use of health information tools to clinical decision making among clinical specialists in OAUTH. The table also shows a coefficient of multiple correlation of R $=.390$ and a multiple $\mathrm{R}^{2}$ of .152 . This means that $15.2 \%$ of the variance was accounted for by two predictor variables when taken together. The significance of the joint contribution was tested at $\alpha=0.05$. The table also shows that the analysis of variance for the regression yielded F-ratio of 22.975 (significant at 0.05 level). This implies that the joint contribution of the independent variables to the dependent variable was significant and that other variables not included in this model may have accounted for the remaining variance.

The findings agreed with Kawamoto and Lobach (2005) who stated that data should be sifted, coordinated, and introduced such that underpins the current work process, permitting the client to settle on an educated choice rapidly and to take action on that decision. The joint contribution of access and use of health information tools to clinical decision making was then seen in the light of established literature to be significant. 
Table 21 Summary of Regression analysis showing the joint contribution of access and use of health information tools to clinical decision making among clinical specialists in OAUTH

\begin{tabular}{lllll} 
R & R Square & $\begin{array}{l}\text { Adjusted } \\
\text { Square }\end{array}$ & $\begin{array}{l}\text { Std. Error of } \\
\text { Estimate }\end{array}$ & the \\
\hline .390 & .152 & A N O V A & .146 & 5.6773
\end{tabular}

\begin{tabular}{|c|c|c|c|c|c|c|c|}
\hline Model & $\begin{array}{l}\text { Sum } \\
\text { Squares }\end{array}$ & of & DF & $\begin{array}{l}\text { Mean } \\
\text { Square }\end{array}$ & $\mathbf{F}$ & Sig. & Remark \\
\hline Regression & 1481.066 & & 2 & 740.533 & 22.975 & .000 & Sig. \\
\hline Residual & 8251.443 & & 256 & 32.232 & & & \\
\hline Total & 9732.510 & & 258 & & & & \\
\hline
\end{tabular}

Hypothesis four: There is no significant relative contribution of access and use of health information tools to clinical decision making among clinical specialists in OAUTH

Table 22 revealed the relative contribution of access and use of health information tools to clinical decision making among clinical specialists in OAUTH, expressed as beta weights, viz: access to health information tools $(\beta=.211, \mathrm{p}<.05)$ and use of health of information tools $(\beta=.224, \mathrm{p}<.05)$. Hence, it could be deduced that access and use of health information tools were significant i.e. could independently and significantly predict clinical decision making among clinical specialists in the study. The null hypothesis was therefore rejected.

The findings agreed with the position of Driven Health System (2013) that rapidly increasing growth in diagnostic and treatment options accelerated still more by advances in genomics and proteomics and the burgeoning amount of available clinical data that present a constant and ongoing gap between practice and potential. According to them, this hole will extend except if an efficient exertion is embraced to create and apply instruments that can quicken the catch, appraisal, approval, interpretation, and ongoing conveyance of best accessible, fittingly customized proof for purpose of care choices by wellbeing laborers. Hence, the relative contribution of both access and use of health information tools to clinical decision making were found to be significant. 
Table 22 Summary of regression analysis showing the relative contribution of access and use of health information tools to clinical decision making among clinical specialists in OAUTH

\begin{tabular}{llllll} 
Model & \multicolumn{2}{l}{ Unstandardized Coefficient } & $\begin{array}{l}\text { Standardized } \\
\text { Coefficient }\end{array}$ & T & Sig. \\
\cline { 2 - 5 } & B & Std. Error & Beta Contribution & \\
\hline (Constant) & 22.890 & 2.484 & & 9.216 & .000 \\
Access to HIR & $6.203 \mathrm{E}-02$ & 0.21 & .211 & 2.905 & .004 \\
Use of HIR & $5.443 \mathrm{E}-02$ & 0.18 & .224 & 3.084 & .002
\end{tabular}

\subsection{Summary, Conclusion and Recommendation}

This chapter presents the summary, conclusion and recommendations based on the findings of the study and provides the contribution of the study to knowledge.

\subsection{Summary of the findings}

Based on the research questions answered:

1. The CT Scan, ECG machine, Incubator, Orthoscopic, Radiograph, GSM telephones, ipad, ipod, Microscope and Computer framework were the significant wellbeing data assets open for clinical dynamic among clinical experts in the investigation

2. The degree of openness to wellbeing data assets for clinical dynamic among clinical experts in OAUTH was high.

3. The wellbeing data assets for clinical dynamic are profoundly open.

4. The degree of utilization of wellbeing data assets for clinical dynamic among the clinical experts in OAUTH was high and the example of utilization was consistently.

5. The recurrence of utilization of wellbeing data assets for clinical dynamic among the clinical experts was high and the example of utilization was consistently.

6. The degree of utilization of different center abilities of clinical dynamic among clinical experts in the examination was high.

7. The negative/conflicting government approaches, financial status of clinical subject matter experts, no social government assistance plot, absence of satisfactory subsidizing, absence of prepared work force in wellbeing data administrations conveyance, wellbeing data sources are not effectively available, helpless bundling of wellbeing data administrations, absence of heath data proficiency among the clinical subject matter experts and absence of sufficient expert abilities were the significant difficulties obstructing the utilization of heath data assets among clinical experts in OAUTH.

8. There was huge connection between admittance to wellbeing data assets and clinical dynamic among clinical experts in OAUTH.

9. There was huge connection between the utilization of wellbeing data assets and clinical dynamic among clinical experts in OAUTH.

10. There was huge joint commitment of the free factors to the reliant variable. 
11. Access and utilization of wellbeing data assets were huge and could freely and essentially anticipate clinical dynamic among clinical experts in the investigation territory.

\subsection{Conclusion}

The CT Scan, ECG machine, hatchery, orthoscopic, radiograph, GSM telephones, ipad, ipod, magnifying instrument and PC framework were the significant wellbeing data assets open for clinical dynamic among clinical experts in the examination. The degree of openness to wellbeing data assets for clinical dynamic among Clinical experts in OAUTH was high. The wellbeing data assets for clinical dynamic is profoundly open. The degree of utilization of wellbeing data assets for clinical dynamic among Clinical experts in OAUTH is high and the example of utilization was consistently. The recurrence of utilization of wellbeing data assets for clinical dynamic was high likewise and the example of utilization was consistently. The degree of utilization of different center aptitudes of clinical dynamic among found by the investigation was to a serious degree. The ominous/conflicting government strategies, financial status of clinical subject matter experts, no social government assistance conspire, absence of satisfactory subsidizing, absence of prepared work force in wellbeing data administrations conveyance, wellbeing data sources are not effectively open, helpless bundling of wellbeing data administrations, absence of heath data proficiency among the clinical trained professionals and absence of sufficient expert aptitudes were the significant difficulties hindering the utilization of heath data assets among clinical experts in OAUTH. There was huge connection between admittance to wellbeing data assets and clinical dynamic among clinical experts in OAUTH. There was huge connection between utilization of wellbeing data assets and clinical dynamic among clinical experts in OAUTH. There was huge joint commitment of the free factors to the needy variable. Access and utilization of wellbeing data assets were critical and could autonomously and altogether foresee clinical dynamic among clinical experts in the examination territory.

\subsection{Recommendations}

In view of the discoveries of this examination, the accompanying suggestions were made:

i. Although the degree of availability of wellbeing data assets for clinical dynamic among clinical experts was high exertion should be strengthened to guarantee that wellbeing data assets are more open to clinical trained professionals

ii. The degree of utilization of wellbeing data assets for clinical dynamic among clinical experts was supposedly high however there was still opportunity to get better among the clinical trained professionals

iii More attention should also be paid to the use of health information tools among the clinical specialists as the pattern of usage could increase from weekly basis to either daily or by weekly basis

iv Clinical specialists should equip themselves through training, seminars, conferences and various capacity building programmes to improve on their core skills for CDM

\subsection{Limitation of the study}

Clinical specialists were friendly and accommodating but their tight schedule and ethical consideration made data collection a little bit difficult. Another limitation was reliance on reported, rather than observed behaviour of the respondent 


\subsection{Contributions of the study to knowledge}

This study has provided information on the different types of information tools accessible for clinical decision making among clinical specialists in the study area. It has also provided empirical evidence for stakeholders in health information profession on clinical decision making in OAUTH especially on health information tools. This study has contributed to the literature in the area of information tools access, use and clinical decision making. The conceptual model for this study was another contribution to knowledge which could be adopted for further studies by any researcher in the future.

\subsection{Suggestion for further studies}

The following suggestions are made for further research in the area of concern for this study.

i. This study was restricted to clinical decision making among clinical specialists in Obafemi Awolowo University Teaching Hospital, Ile-Ife. Similar studies should be carried out with a different population from areas such as South East federal university teaching hospitals.

ii. Further exploration could be led to research the sorts of wellbeing data assets favored for clinical dynamic among clinical experts in Obafemi Awolowo University Teaching Hospital (OAUTH) and why.

iii. Studies could also be conducted on the effect of health information tools on clinical specialists' clinical dynamics in other teaching hospitals and tertiary health institutions. 


\section{Acknowledgements}

He has made everything beautiful in His own time, thus making him the keeper of promise. All honour and adoration be to God Almighty for helping me this far academically, notwithstanding my frailties. He has truly proven Himself to be an architect of all good things. May his Name be glorified forevermore.

My unalloyed gratitude goes to a professional and academic mentor who doubles as my major supervisor, Dr S.O. Adeyoyin for the deep interest shown towards my academic pursuit. I appreciate his quest to make this research easy for me through academic tutelage. I am also grateful to my co-supervisors Dr. O.G.F. Nwaorgu and Dr C.I. Alarima for their invaluable contributions towards the research work.

I sincerely appreciate my parents, Mr and Mrs Adekunle Adegboye for their unconditional love, perseverance, endurance, moral and financial support toward my life. Also my brother Oluwatayomi Adegboye for constantly reminding me to stay focused and never look back

The concerted efforts of all the lecturers in the department during the classwork, pre-field and post-field seminars had given this research work a positive direction and I am sincerely grateful for all their contributions. Also, a special thanks to the Head of Department, Professor Comfort Onifade for constantly asking about the progress of this research work.

It will be a great disservice, if I fail to appreciate my other colleagues for their support. God bless you all. 


\section{References}

Adeyoyin S.O, Ekundayo, E.O, Akinlade, O. and Ewulo, O.R. 2019. Health Information Provision for the Vulnerable Orphans in Ogun State Nigeria. Library Philosophy and Practice. Retrieved from http://digitalcommons.unl.edu/libphilprac/2371 on November 232018

Adeyoyin, S.O. 2017. Use of Reproductive Health Information among University

Undergraduates in Ogun State, Nigeria. International Journal of Knowledge Content

Development \& Technology, 7(3):49-65.

Adeyoyin S.O and Oyewusi 2015. Needs and Utilisation of Health Information among young Adults in Abeokuta, Ogun state, Library philosophy and practice 1296 Retrieved from http://digitalcommons.unl.edu/libphiprac on march 3rd 2019

Aramide, K.O., Oduroye A. and Alagbe A. 2012: Effect of Health Information Literacy on the Attitude of Women towards Family Planning

Aspinall S, Good C, Glassman P\& Valentino M 2008. The evolving use of cost-effectiveness analysis in formulary management within the Department of Veteran Affairs. Med Care (7 Supplement) II20II26.

Afolayan O. T. and Oyekunle R. A. 2014. Availability, Accessibility and Frequency of Use ICT by health Professional in Florin, Metroplolis. Covenant Journal of Informatics and communication technology Vol 2(1) pg 1-13 Retrieved from

https://cujournals.convenantuniversity.edu.ng/index:php/syict/issue/view/13. On March 142019.

Aftanna R and Ezema I 2005 Library and Information Service. A practical approach $2^{\text {nd }}$ ed. Enugu mikon press.

Aguolu, C.C. and Aguolu, I .E 2002. Libraries and Information Management in Nigeria. Seminal Essays on Theme and Problems. Ed-Linform Service, Maiduguri Retrieved from https://www.scirp.org on January 192019.

Ajayi, W.A 2013. Impact of Health Informatics on Nurse's Computer Skill and Role of the Library. The library vol 31 (2) Pg 157 - 166 Retrieved from. https://jor.org/10.1002/bdm.481 on jan 23 2019.

Ali M, Talpur M H, Alamgir A and Javad MA 2015. Organisational Information Theory a mechanism to ensure community participated: A case study of a Malaysian NGO. Nice Research Journal. Vol 8 (31) Pg 1-15

Ami A, Annual symposium proceeding Archive pg 1334-1140 Retrieved from https://www.ncbl.nlm.gov/pmc/articles/pmc/44199361 on Feb 262019

Anderson L., Panos V. and Spencher C. 2004 Health Needs of Young Offenders, Journal of Child health care. Vol 17 (2)pg 40- 48 Retrieved from https://doi.org/10.1177/1367493504041873 on february 16 2019

Bakalis N, Bowman G. S and Porock D. 2003 Decision Making in Greek and English registered nurses in coronary care unites, international Journal of nursing studies Vol 40(7) Pg 749-760 Retrieved from https://www.ncbl.nlm.nih.gov on Feb 172019

Bawden D 2008. The Worlds of Health Information. Journal of information science, vol 23 (2) Pg 125 - 133 Retrieved from https://doi.org/10.11771016555150202800106 on 18 march 2019. 
Bell C. M and Chapman R. H et al. An oFF-the-shelf help list: A Comprehensive Catalog of Preference Scores from Published Cost- Utility Analyses, Med Decision making, 21(4): 288-294 Retrieved from https://books.google.com.ng on March 282019

Bergman J, Platonov V, Dukeov I and Luukka P 2016 Information Processing Approach in Organisational Cognitive Structure: Relationship Between Top and Middle Managers Cognitions. International Journal of Information System and Change Vol 7 (4) Retrieved from https://www.researchgate.net/publication/308766088 on 30th February 2019

Bigdeli M and Javadi D 2013 Health Policy and Systems Research in Access to Medicines, Health Research Policy System Vol 11(37) Retrieved from https://doi.org/10.118611478-4505-11-37 on April 25 2019

Brandon D 2004 Decisions journal of information. Academy management, Vol 48 Pg 119 - 148 Retrieved from https://book.google.com.ng on April 122019.

Bucknall T 2003 The Clinical Landscape of Critical care Nurses Decision Making. Journal of advance nursing vol. 43(3) Pg 310 - 319 Retrieved from https://bookgoogle.com.ng on March 172019.

Callsway S, Akilo H and Bierman K 2013 Impact of a Clinical Intervention, Documentation Efforts and Cost, journal of decision support systems vol 48 (9) Pg 744 - 752 Retrieved from https://www.ncbi.nlm.nh.gov on March 182019.

Case D. O and Connor LG 2018. What is the use? Measuring the Frequency of study of information outcomes, Journal of the Association for Information Science and technology. Early view.

Cassey K, Fink R, Krugman M and Pospst J 2004 The Graduate Nurse Experience, Journal of nursing administration, vol 34(6) Pg 303 -311 Retrieved from https://www.resarerchgate.net on February 19 2019.

Chapman G 2004 the Psychology of Medical Decision Making. In koechler DJ, Harvey M (eds) Blackwall handbook of judgment and decision making. Blackwell Publishing, maiden M.A, P 585- 604 Retrieved from https://books.google.com.ng on April 172019.

Chapman S 2004. Advocacy for public health, Journal of Epidemiology and Community health, London BMJ books, retrieved from https://jech.com on $14^{\text {th }}$ march 2019.

Chapman R, Berger M, \&Weinstein M, Weeks, Goldie and Newman, C 2004 When does quality-adjusting life-years matter in cost-effectiveness analysis? Health Economics. Vol13 Pg 429-436.

Charles R., Sarmeinto R., Gavino A. and Fontelo P. 2014. Confidence and Information Access in Clinical Decision making, an examination of the cognitive process that affect the information seeking behaviours of physicians

Chimmock P, Nandi A and Clarke M 2005 is Evidence Based Medicine Relevant to the Developing World, Advance Access publication. Vol 2 (3) Pg 321-324 Retrieved from

https:// doi:10.1093/ecam/neh114 on March 142019

Choo, S 2007. Using Training and Development to Affect Job Satisfaction within Franchising. Journal of Small Business and Enterprise Development, Vol 14 No 2 Pg. 339- 352 Retrieved from http:// doi.org/10.1108/14626000710746745 on March 19, 2019

Choudhry NK, Fletcher RH and Soumerai R. 2005 Sytematic Review: The relationship between clinical experience and quality of health care, Arin Intern medicine Vol 101(142) Pg 260-273

Christakis N, and Fowler J 2007 The Spread of Obesity in a Large Social Network over 32years Journal of medicine Vol 357(4) Pg 370-9 Retrieved from https://www.ncbi.nlm.nih.gov on May 62019.

Cleveninga F, Gorter K, Donk M, and Ruthen G 2007. Combined task delegation, computerized decision 
support and feedback information improve cardiovascular risk for the type 2 diabetics patients. A cluster randomized trial in primary care, Journal of diabetics care vol. 31 (12) Pg 14 - 19 Retrieved from https://www.researchgate.net on Feb 232019.

Codgdul Kwoj 2003. Information Needs and Information Seeking in Primary care: a case study of nurse Practitioners, National network of libraries of medicine. Retrieved from https://www.ncbl.nim.nih.gov on $19^{\text {th }}$ January 2019.

Cogdill K 2007. Introduction public health information outreach. Journal of the medical library association, vol.95 (3) p 290 - 292. Retrieved from https:www.ncbi.inlm.nib.gov on march 142019.

Connoly T, Arkes H and Hammond K. 2000 Judgment and decision making and interdisciplinary reader, $2^{\text {nd }}$ edn Cambridge University press. Retrieved from https://boo.google.com.ng on April 242019.

Corcoran S 2009 Task Complexity and Nursing Expertise as a Factor in Decision Making, Nursing research vol. 35 (2) pg 107-112 Retrieved from https://book.google.com.ng on March 182019.

Couthard M 2007 What is Evidence Based Medicine: Journal of clinical and experimental optometry vol 90 , issue 4 Pg 126-130 Retrieved from https://doi.org/10.1111/j.444 - 0938.2007.001324 on April 24 2019.

Daniel G and Oyetunji M 2013 Nursing Informatics a key to improving Nursing and Midwifey, vol 5 (5) Pg 90-98

Davies K. 2007 The Information- Seeking behavior: a review of the Evidence, Health Information and libraries Journal, Vol 13 Pg 78- 94 Retrieved from https://www.doi.10.111/J.14711842.2007.00713.4 on March 182019

Dawes R and Haste R 2010. Rational Choice in an Certain World: the PSYCHOLOGY of JUDGMENT and DECISION MAKING, Journal of behavioral decision making vol 18 (1) Pg 1-27 Retrieved from https://dor.org/10.1002.1bdm.481 on march 282019.

Dutta-Bergman M 2004 Primary sources of health Information Comparisons in the Domain of Health Attitudes, health cognitions and health behaviors, Journal of health communication Vol 16(3) pg 273- 288 Retrieved from https://www.ncbl.nlm.n,h-gov on May 242019

Edward I, Jones M and Higgs J 2004 what is collaborative reasoning ? advances in physiotherapy vol 6, P 7083 Retrieved from https://book.google.com.ng on march 142019.

Ellis Y and Sharp V. 2005. Theory and Practice in value management Vol. 25. Retrieve from doi.10.1080/01446190601161473 February 172019

Elsteen A and Schwartz A 2000. Clinical Reasoning in Medicine in: Clinical Reasoning in Health professions, $2^{\text {nd }}$ edn. Butterworth-heinman, oxford, pg 25-106 Retrieved from https://book.google.com.ng on February 262019.

Ewing R and Smith D 2001 Doing, Knowing, Being and Becoming: The Nature of Professional Practice, Journal of professional practice. Backwell science vol 18(2) 16-28.

Felcher AH, Gold R, Mosen D.M and Stone-Burner A 2017 Decrease in Unnecessary Vitamin D testing using Clinical Decision Support Tools, journal of the America medical informatics vol. 24 (24) pg 776 - 780 retrieved from https://idor.org/10.1093/jania/ocw182 on Feb 192019.

Folorunsho, A. L. and Haruna I. 2005. A Survey of information needs and

seeking behaviour of Kwara State House of Assembly Legislators. Middle Belt, Journal of Library and Information Science, 5 (2) 52.

Fonkych K and Taylor R. 2003. The State and Pattern of Health Information Technology Adoption, Journal of $R$ and D Corporation. Retrieved from http://www.rend.org/ on February 162019

Fox S and Jones S 2009. Patients, Clinical Decisions and Health Information Management in the information age, National Academics Press 28(3) Pg 43-48 Retrieved from https://www.ageofpersonalisedmedice.org/center/policy/hit.asp on March 142019

Friedman C. P and Jeremy C. w 2005 Evaluation method in Medical Information springer: New York

Fritz J.M. Child J.D, Wainner R.S and Flynn TW 2012 Primary Care of Patience with Low Back pain to 
physical therapy : impact on future health care utilisation and costs, Health service research vol 37 (25) pg 2114 - 2121 Retrieved from https://www.ncbi.nlm.nil.gov on May 152019.

Gans D, Kralweki J, Hammons T and Dowd B 2005. Medical groups adoption of electronic health record and information system, Journal of health affairs Vol 25 (5) pg 1323 - 1333 retrieved from https://doi.org/10.1377/hlthaff.24-5.1323 on Feb 2019

Garg AX, Adhi Kari Nk, Mc Donald H, Rosas R, Arellano MP, Deverax PJ, Beyere J, Sam J and Haynes RB 2005. Effect of Computerized Clinical Decision Support Systems on Practitioner performance and patient outcomes: JAMA 293 (10) Pg 1223-1238 Retrieved from https://www.ncbi.nih.gov on Feb 182019.

Gatero G. 2010. Utilisation of ICT for Accessing Health Information by Medical Professionals in Kenya, Journal of Health Informatics in Developing Countries Vol 5(1) Pg 1-7 Retrieved from https://www.jhidc.org/index.php/jhldc/article/view/ss on March 142019

Gerrish K, Ashworth P, Lacey A and Bailey J 2008. DEVELOPING EVIDENCE Based Practice EXPERIENCE of Senior and Junior Clinical Nurse, Ajan special section global nursing. Vol 62 (1) pg 62-73 retrieved from Https://idoi.org/10.1111/J.136 5-26 48.2007.04579.4 on February 232019

Griffths P 2010. A Community of Practice the Nurse role on a Medical Assessment unit, journal of clinical nursing, vol $20 \mathrm{Pg} 247-54$

Hafkin N and Taggart N 2010. Gender Information Technology and Developing countries, Journal of computer-mediated communication Vol 15(3) pg 500-525 Retrieved from https:// doi.org/10.1111/J. 1083-6101.2010-01515 on April 142019

Hagbaghery M.A, Salsal L, M, and Ahmadi F 2004 The factors Facilitating and Habituating effective Clinical Decision Making in Nursing. BMC nursery vol 3 (2) pg 26 - 29 Retrieved from https://www.ncbi.nlm on March 142019.

Hammond K 2000 Human Judgment and Social Policy Irreducible Uncertainty, Inevitable Error. Oxford University Press, New York.

Hay J, Coups E, Ford J and D. Bonaventura M. 2009 Exposure to mass media health information, skin cancer beliefs and sun protection behavior in a united states probability sample, Journal of the American of Dermotology Vol 61 (5) Pg 783-789 Retrieved from https:// doi.org/10.1016/ J. Jaad.2009.04.023 on May 162019

Hedberg B, and Larson U 2004 Environmental Element Affecting the Decision Making Process in Nursing Practice, journal of clinical nursing, vol 13 (3) Pg 316-324 Retrieved from https://book.google.com.ng on Jan 142019.

Hersh W 2010 The Health Information Technology Workforce, Journal of Applied Clinical informatics Vol 1(2) Pg 197- 212 Retrieved from httP://www.billhersh.info on April 122019

Hollander M. and Morano D. 2012. The economics of health care quality and medical errors. Journal of healthcare Finance Vol 39(4) Pg 1-13 Retrieved from https://www.ncbl.nlm.nih.gov/pubmed/23155736 on March 172019.

Hughes S, Burke J and Hanson D 2008 Urban teenagers, Health Information and Public Library websites, Journal of School Health Vol 6 (24) pg. 35-42 Retrieved from https://www.researchgate.net on March 272019

Ifinedo P 2012, Technology Acceptance by Health Professionals in Canada: an analysis with a modified UTAUT model $45^{\text {th }}$ Hawai international conferences in system science Retrieved from https://pdfs.semanticsscholar.org/4227/745bb7742917dc7a83c7Fb286f6137sds.pdf on March 12 2019

Islam S and Ahmed Z 2012 The information needs and information seeking behavior of rural dwellers. A review of research, Journal of International federation of library Associations and Institutions, Vol 38 (2) pg 137-147 Retrieved from https://journal.sagepub.com on April 272019 
Jacobs W, Amuta A and Jeon K 2017 Health Information seeking in the digital age, Journal of Health communication. Vol 3 (1) Pg 232-247 Retrieved from https:// doi.org//0.1080/10410236.2014.9799.76 on May 172019

Jansson I and Forsberg A 2016 how Nurse and ward manager perceive that evidence based source are obtained to inform relevant nursing interventions, JAN SPECIAL SECTION BGLOBAL NURSING vol 26 (5-6) Pg 769-776 Retrieved from https// doi.org/10/1111/jpocn/3095 on March 232019.

Kahane S. 2011 must appear to be all known patients and family physicians perspectives on information seeking during consultation can form physicians Vol 57 pg 2778- 236 Retrieved from https://www.ncb.nlm.nih.gov/pmc/articles on March 22019

Kaplan B and Kimberly D 2009. Health IT success and failure, recommendation from literature and AMIA workshop Journal of medical information Association Vol 16 (3) pg 291-299 retrieved from https://www.ncbi.nlm.nih.gov/pmc/articles/pmc 27322441 on March 222019

Kassirer J, Angell M. 2005. The Journal's policy on cost-effectiveness analyses. New England Journal of Medicine 331:669-670.

Kawamoto K and Lobach DF 2005 Design, implementation, Use and Preliminary Evaluation of Sebastian, a Standards - based web service for clinical decision support. Amia annus symp- proc $380-4$ retrieved from https://digital.org.gov on May 142019.

Kaytazi M. 2012 Information Inadequacies: the lack of needed information in human, social and industrial affairs, F I P Advances in Communication and information technology Vol 386 Pg 320-329 Retrieved from https://doi.org/10.1007/978-3-642-33332-3-29 on February 172019

Kelly M, Su K and Britigan D 2015 Disparities in Health information Access: result of a country wide surety and implications for health communication, Journal of Health communication 31 (5) pg 575- 582 retrieved from https://doi.org//10.1080/10410236.2014.979976 on May 142019

Lawton A and Burns J. 2015 A Review of competencies needed for health Librarians- a comparison of Irish and International Practice, Journal of health information and Libraries journal Vol 32 ( 2) Pg 84-94 Retrieved from https://schorlar.google.com on February 122019

Lewis M 2003. Decision making task complexity model development and initial testing journal of nursing education, vol36(3) pf $114-120$ retrieved from https://book.google.com.ng on march $17^{\text {th }} 2019$

Limberg L, Sundin O and Talga S 2012, Three Theortrical Perspectives on Information literacy. Human IT Vol 11 (2) Pg 93-130

Lobach D., Ganders G. D, Bright T. J., Wong A and Erin R. D 2012. Enabling Health Care decision making through clinical decision support and knowledge management retrieved from https://digital.

Mallinge, J. B, Griggs J.J and Shields C. G. 2005 Patient- centered care and breast cancer survivors satisfaction with information. Journal of Education and Counselling, Vol. 57 Issue 3 P 342-349 Retrieved from https://doi.org/10.1016/J. pec.2004.09.009 on 15 February, 2019

Marcelo, C. Y and Jimen Alberti 2013 Raw materials availability, distribution and human exploitation strategies in coastal north patasonia. $5^{\text {th }}$ symposium stones written in stones. Intention symposium on charts and other knapplable. Retrieved from https://www.researchgate.net on January 202019

May B 2003 One decision making. Physical therapy, vol 76(11) pg 1232 - 1240 retrieved from htpps://book.google.com.ng on Feb $14^{\text {th }} 2019$.

McCaushey and Cullum 2001. Clinical Issues Advanced Practice in Acute and Critical Care. 12 (4) 520-528. Retrieved from https://www.ncbl.nln.nih.gov

Monique. V. C 2004. Adolescent Pregnancy, Exclusive a Public Health Issue, American Journal, Health, 
Social, Economic and gender perspectives Vol 12 (4) retrieved from www.un.org.wubbernhoost on $17^{\text {th }}$ January 2019

Moon J, Hossain, M and Shin J 2012. Analysis of agricultural information in korea: the government role in bridging the digital divide. Journal of information development, vol 28 (2) p $102-116$ retrieved from

Oltman S.M 2009. Information Access Indianna University, Springer. Retrieved from https://bpm.ils.indiana.edu on March 162019

Onayite R 2015. Health Information management personnel service Quality: patients' perception in tertiary hospitals in Ogun State, Nigeria, School of education and humanities international conference.

Otero P, Hersh W. Luna D and Gonzalez F 2002. Medical informatics distance learning course from latin America. Journal of method of information in medicine, vol 49 (3) p 310 - 315 retrieved from https://researchgate.net on May 172019.

Oxford English Dictionary 2003

Paterson M and Higgs J 2001, professional practice judgment artistry, Association paper 3 center for professional education advancement, university of Sydney.

Peul W, van den Hout W, Brand R \& Thomeer R, Koes B 2008. Prolonged conservative care versus early surgery in patients with sciatica caused by lumbar disc herniation: two year results of a randomised controlled trial. BMJ 336:1355-58.

Pfeiff J, Johnson W, and Gimbel - Sher K, 2004 strengthening health systems in poor countries, Journal of public health, vol 98(12) 2134 -2140, retrieved from https://ncbi.nlm.nih.gov on April 232019.

Romano M, Randall B and Stafford S. 2011 Electronic health Records and clinical decision support systems, JAMA internal medicine Vol 171 (10) pg 897- 903 Retrieved from http:// www. Do1:10.100//archinternmed.2010.527 on March 18, 2019.

Rosenzweig, M. D 2000 Myocardial Hypertrophy in a Young Woman, Echocardiography, Vol. 17, Issues 5. Retrieved from https://doi.org/10.111/J.15408175.2000.tb01163. on January 182019.

Sackett D. L, Sharon, E. S, Richardson. W. S, William, R and HAunes R. B 200-. Evidence-based Medicine. How to practice and Tech EBM. $2^{\text {nd }}$ ed. Churchill livingstone, p261. Retrieved from https://doi.org/10. 1093/ chinchem/ 47.9.1747 on Jan 192019

Samson O, Alarape and Aramide O. 2015. Health Information literacy and maternal Anxiety of rural child bearing women in Nigeria, journal of business management vol. 20 (8) pg 01-06 retrieved from www.iosrjournal.org on May 172019.

Samuel G. S., Wolf M. S and Wagner C. U. 2010. Socioeconomic status statistical confidence and patient provide communication. An analysis of the Health Information. Journal of Health Communication, International Perspectives, Vol. 15 Issues 3 p 169- 185. Retrieved from https:// dol.org/101080/10810730.2010522690 on February 192019.

Sen B. and Taylor R. 2007 Determining the Information Needs of small and medium sized enterprises, information Research Vol 12 (4) pg 329 Retrieved from http://information.net/ir/12-4/paper329 on March 152019

Schiavo R. 2007 Health Communication from Theory to Practice. America psychological Association. Second Edition Retrieved from https://psyc.apa.org on March 142019

Schilling K 2012 Health librarian an introduction, journal of medical library Association, vol 97 (4) pg 273 279 retrieved from https://booksgooglecom.ng on March 172019.

Sketcher 2017. Guide to informed decision making in health care. Journal of state of Queens health, $2^{\text {nd }}$ 
edition. P 8 - 12. Retrieved from https://creative common.org/licenses/by-nc/2.5/au/ on May 17, 2019.

Smith M 2006 clinical decision making in acute care cardiopulmonary physiotherapy unpublished loctoral thesis university of Sydney.

Smitt M, Higg J and Ellisse 2010 Effect of experience on clinical decision making by cardiorespiratory physiotherapist in acute care settings. Physiotherapy theory pract. Vol 26 (2) pg 89 - 88 retrieved from https://ncbi.nlm.nih.gov on April 262019.

Soman M 2004 Framing, loss aversion and mental accounting, journal handbook and decision making blackwood publishing, maiden p $379-398$ retrieved from https://book.google.com.ng on Feb $17^{\text {th }}$ 2019.

Sox H, Blatt M \& Higgins M, Marton K : 2007. Medical Decision Making. 2nd ed American College of Health workers; Philadelphia

Spenceley S, Leary K, Chizalosky L, Ross A and Estabooks 2008. SOURCE of INFORMATIONAL used by nurses to inform practices; international journal of nursing studies vol 45 Pg 9:54-970 Retrieved from www.elseview.com/locate/ijnurstu on march 232019

Thompson C, Cullum N and McCaugtey D 2004. Nurses Information use and clinical decision making. The real world potential for evidence based decisions in nursing, Evidence based nursing Vol 7 Pg 6672.

Thompson N, Bevan J and Sparks S 2012 Healthcare reform information-seeking: relationships with uncertainty, uncertainty discrepancy and health self- efficacy, Journal of communication in health care Vol 5(1) pg 4-12 Retrieved from www.chapman.edu on March 142019

Timmermans S. and Mauk A. 2005. The promises and pitfalls of evidence- based medicine, Health AFF, Vol 24 pg 18- 28 Retrieved from https://www.ncbl.nlm.nih.gov/pmc/articles/pmc4419936 on March 26 2019

Tosteson A, Skinner J, Lurie J, Andersson G and Berven S, 2008. The Cost Effectiveness of Surgical Versus Nonoperative Treatment for Lumbar Disc Herniation Over Two Years. SPINE; 33 (19) 1-8.

Van Osch S, Wakker P, van den Hout \& Stiggelbout A 2004. Correcting biases in standard gamble and time tradeoff utilities. Medical Decision Making; 24 (511-517)

Watts C and ibegbulam 12006 Access to electronic healthcare information tools in developing countries, Journal Indexing \& metrics Vol 32 (1) pg 54-61 Retrieved from http:/ dol.org/10.117710340035206063903 On Feb 172019.

Weinstein J, Lurie J and Tosteson T 2006. Surgical vs nonoperative treatment for lumbar disck herniation: the Spine patient Outcomes Research Trial (SPORT) observational cohort. JAMA;296:2451-9.

Weinstein M, Siegel J, Gold M, Kamlet M, Russell L, Evans, Tavakoli and Crawford 2004. Recommendations of the panel on cost-effectiveness in health and medicine. JAMA;276(15):125358.

Wells' S and Bullen C. 2008 A near miss. The importance of context in a public health informatics project in a new Zealand case study, Journal of the American medical informatics association vol. 15 (2) pg 701 - 704 retrieved from https://www.resarchgate.net on Feb 182019.

Whitney S 2003 A new model of medical decisions. Exploring the limit of hard decision making, Journal of 
medical decision making, vol 23 Pg 275-280 Retrieved from http://book.google.com.ng on Feb 26 2019.

Willians N and Roseline O 2013. Information needs and seeking behaviours of nurses at the university college hospital, Ibadan Nigeria, African Journal of Library, Archives and information science, Vol 19 (1) Retrieved from www.academic journals.org on April 142019

Wilson B. 2007. Nurses Knowledge of pain, Journal of Clinical Nursing, Vol. 16, issue Retrieved from http://doi.org/10.1111/J.1365-2702.2007.01692.X on Feb 152019

World Health Organization 2007

World health organization 2006. HINARI national health information system. Retrieved Feb 172019. www.who.int/hinari/about.en/.

Wu I, Li J, and Fu C 2011 The adoption of mobile healthcare by hospital professionals, journal in decision support systems vol.51 (3) pg 587 - 596 retrieved from https://www.resaerchgate.net on March 27 2019.

Yogarajan V, Mayo M and Pfahringer B 2018. Privacy Protection for Health information Research in New Zealand District Health Boards Journal of New Zealand Medical Association 131 (1485) Pg 19-26. Retrieved from researchcommons.waikato.ac.nz April 162019

Zheng K, Abraham J, Novak L, Reynolds T.L and Gettinger S 206. A survey of the literate on unintended consequence associated with health information technology medical informatics vol 1 pg 13-29 retrieved from https://www.ncbi.nih.gov on march 232019. 